\title{
Amphipathic Dendritic Poly-peptides Carrier to Deliver Antisense Oligonucleotides Against Multi- drug Resistant Bacteria in Vitro and in Vivo
}

\section{Zhou Chen}

Fourth Military Medical University: Air Force Medical University

\section{Yue $\mathrm{Hu}$}

Fourth Military Medical University: Air Force Medical University

\section{Xinggang Mao}

Fourth Military Medical University: Air Force Medical University

\section{Dan Nie}

Fourth Military Medical University: Air Force Medical University

\section{Hui Zhao}

Fourth Military Medical University: Air Force Medical University

\section{Zheng Hou}

Fourth Military Medical University: Air Force Medical University

\section{Mingkai Li}

Fourth Military Medical University: Air Force Medical University

Jingru Meng

Fourth Military Medical University: Air Force Medical University

Xiaoxing Luo

Fourth Military Medical University: Air Force Medical University

Xiaoyan Xue ( $\nabla$ xxy.0707@163.com )

Fourth Military Medical University

\section{Research Article}

Keywords: Antibacterial strategy, Antisense, Dendritic poly-peptides, Multidrug-resistant bacteria, Nanoparticles, Delivery, Oligonucleotide

Posted Date: November 10th, 2021

DOI: https://doi.org/10.21203/rs.3.rs-1020707/v1

License: (c) (1) This work is licensed under a Creative Commons Attribution 4.0 International License. Read Full License 
Version of Record: A version of this preprint was published at Journal of Nanobiotechnology on April 2nd, 2022. See the published version at https://doi.org/10.1186/s12951-022-01384-y. 


\section{Abstract}

Background: Outbreaks of infection due to multidrug-resistant bacteria, especially gram-negative bacteria, have become a global health issue in both hospitals and communities. Antisense oligonucleotides (ASOs) based therapeutics hold a great promise for treating infections caused by multidrug-resistant bacteria. However, ASOs therapeutics are strangled because of its low cell penetration efficiency caused by the high molecular weight and hydrophilicity.

Results: Here, we designed a series of dendritic poly-peptides (DPP1 to DPP12) to encapsulate ASOs to form DSPE-mPEG2000 decorated ASOs/DPP nanoparticles (DP-AD1 to DP-AD12) and observed that amphipathic DP-AD2, 3, 7 or 8 with a positive charge $\geq 8$ showed great efficiency to deliver ASOs into bacteria, but only the two histidine residues contained DP-AD7 and DP-AD8 significantly inhibited the bacterial growth and the targeted gene expression of tested bacteria in vitro. DP-AD7 anti-acpp remarkably increased the survival rate of septic mice infected by ESBLs-E. coli, exhibiting strong antibacterial effects in vivo.

Conclusions: For the first time, we designed DPP as a potent carrier to deliver ASOs for combating MDR bacteria and demonstrated essential features, namely, amphipathicity, 8-10 positive charges, and 2 histidine residues, that are required for efficient DPP based delivery, and provide a novel approach for the development and research of the antisense antibacterial strategy.

\section{Background}

Nowadays, multidrug-resistant (MDR) bacterial infections are becoming difficult to cure, especially those caused by the organisms on the World Health Organization priority bacteria list [1-4]. So it is imperative to search for and develop novel strategies to fight against MDR bacteria. With the advantages of high specificity, easy design and synthesis, antisense oligonucleotides (ASOs) based antibacterial technology has emerged as a promising approach to reverse the resistance or inhibit the growth of bacteria by blocking the expression of critical genes [5]. Thus far, numerous functional genes have been validated as potential antisense antibacterial targets, such as vanA (encoding the glycopeptide-resistant related protein) and $a c p P$ (encoding the survival-essential acyl carrier protein involved in fatty acid biosynthesis) [6-8]. Our laboratory also identified several genes, such as $m e c A$, $a c r B$ and $r p o D$ (encoding the survival essential RNA polymerase primary $\delta^{70}$ ), that can be targeted by different types of ASOs. These ASOs can inhibit the expression of targeted genes and ultimately abolish the antibiotic resistance of bacteria or kill bacteria in vitro and in vivo [9-12].

Despite the advantages of ASOs based antibacterial agents and significant technological advancement in oligonucleotide chemical modification, free ASOs without any vector can hardly penetrate the cellular membrane because of their high molecular weight and hydrophilicity. Furthermore, the bacterial cell wall presents another obstacle to ASOs delivery, especially the outer-membrane lipopolysaccharide layer in 
Gram-negative bacteria, which blocks the entrance of antibiotics and other foreign compounds $[13,14]$. Therefore, lacking delivery system seriously hampered antibacterial ASOs clinical application.

Two common strategies were developed for ASOs delivery. One involves the encapsulation of ASOs into nanoparticles (NPs) by using cationic materials, such as lipofectamine 2000 (LF2000), bolaamphiphiles and green tea catechin [11, 14-17], However, thus far, little is known about why these NPs showed a considerably lower delivery efficacy and higher cytotoxicity in bacteria than in mammalians $[18,19]$. Another more widely studied strategy is the conjugation of ASOs with different cell penetrating peptides (CPPs) covalently to generate a new compound ASOs-CPP $[9,10]$. However, even with the currently most effective CPP, RXRRXRRXRRXRXB ( $X$ is 6-aminohexanoic acid and $B$ is $\beta$-alanine), a high dosage of ASOs-CPP is still required for satisfactory therapeutic effect, probably due to the low drug loading capacity of covalent CPPs. In addition, large-scale synthesis and purification of ASOs-CPP products are time-consuming and expensive [18-20].

An alternative strategy used in mammalian cells is to complex ASOs with CPPs non-covalently to form NPs, which exhibited high ASOs loading capacity, low cytotoxicity and low immunogenicity [21]. However, those CPPs/ASOs NPs also showed lower transfection efficiency in bacteria. For example, CADY peptide NPs could deliver ASOs molecular into mammalian cells more efficiently than in bacteria [22]. We assumed that this may be related to the special structure of bacteria, and the successful design of ASOs/peptide NPs for bacteria may require systematic research on the peptide structures and sequences. Various factors, including the geometry structure of peptides, hydrophobicity, Histidine (His) and the number of positive charges, play essential roles in the delivery process in mammalian cells $[19,23,24]$. For example, dendritic peptides hybridized with lipids have higher transfection in mammalian cells compared with their linear counterparts [23], and the melittin peptide with His residues exhibited a higher transfection efficiency than the counterparts without His residues [24].

Here, to systematically study the factors influencing uptake efficiency of peptide NPs in bacteria, we designed a series of dendritic poly-peptides (DPP1-DPP12) with various parameters, including hydrophobicity, the number of positive charges, and DPP amino acid types, to screen DPPs that can efficiently deliver ASOs into bacteria. Then, the antibacterial activity of ASOs targeting acpP delivered by DPPs was evaluated in vitro and in vivo. ASOs was encapsulated by DPP to form 1,2-distearoyl-snglycero-3-phosphoethanolamine-N-methoxy(polyethylene glycol)-2000 (DSPE-mPEG2000) decorated NPs (DP-AD, where AD stands for ASOs/DPP NPs). We demonstrated that amphipathic DPP2, 3, 7 and 8, which contained 8-10 positive charges, showed a notably higher efficiency than hydrophilic DPP1 and DPP6 to deliver ASOs into bacteria, but only DP-AD7 and DP-AD8 containing two His residues showed better gene knockdown and growth inhibitory effect in tested strains in vitro. Importantly, DP-AD7 targeting acpP, significantly increased the survival rate and reduced the bacterial colony forming units (CFU) in the organs of septic mice infected by extended spectrum beta-lactamases producing (ESBLs)-E. coli. Conclusively, for the first time, our research clarified the essential factors required for the assembly of DP-AD with the best delivery performance into bacteria, demonstrating that DPP based non-covalent complexion strategy is a promising approach to deliver antisense antibacterial agents into bacteria. 


\section{Results And Discussion}

\section{The design of DPPs}

To screen the DPPs that can transfect ASOs efficiently into bacteria, we synthesized 12 DPPs with four terminal branches and a linear counterpart by solid-phase peptide synthesis. The DPPs were designed to have different hydrophobicity and positive charge distributions by introducing hydrophobic leucine (Leu), tryptophan (Trp) and alanine (Ala), and hydrophilic cationic arginine (Arg) and lysine (Lys) (Scheme 1, Additional file 1 Figure S1-S3, Tables S1-S2), which are commonly used to confer cell-penetrating capacities on peptides [25-27]. In detail, DPP1, DPP4, DPP5 and DPP6 were hydrophilic, while DPP2, DPP3 and DPP7-DPP12 were amphipathic. The hydrophobic Leu and Trp in DPP1 and DPP6 were replaced with hydrophilic hydroxyl-containing threonine (Thr) and serine (Ser), respectively, to form the strictly hydrophilic DPP4 and DPP5, given that the hydroxyl group may enhance the hydrophilicity and adhesion between bacteria and NPs $[28,29]$. With positive charge distribution as another significant factor determining the delivery efficiency of CPPs [21], different distribution of Arg residues in DPP1 and DPP4, as the primary source of positive charges in DPPs, were used to generate DPP6 and DPP5, respectively, to explore the effects of charge distribution on the delivery efficiency. In addition, the His residues in CPP sequences enhances NPs endosomal escape in mammalian cells [24], thus two Lys residues in DPP3 were replaced by two His residues to generate DPP7 to test whether His could improve DPP transfection efficiency in bacteria. To further clarify the effects of the number of positive charges and His residues in DPP, we designed DPP8-DPP12 based on DPP7 sequence by increasing or decreasing the number of His and Arg residues. The counterpart linear DPP (L-DPP) with the same sequence as DPP7 was also synthesized as the control.

\section{Preparation and characterization of DP-ADs}

DP-ADs were prepared using a two-step protocol (Fig. 1a and Additional file 1: Table S3). Briefly, DPP and ASOs were mixed and incubated at $37^{\circ} \mathrm{C}$ for 30 min, added with DSPE-mPEG2000, and then incubated for another $30 \mathrm{~min}$. In the present study, all ASOs were synthesized by 2'-OMe modified nucleotides. To optimize the molar ratio of N/P (the number of free amino groups in DPP to the number of nucleotides in ASOs) for the preparation, we evaluated DPP/ASOs nanoparticles (AD) prepared with the N/P molar ratio ranging from 1 to 16 by agarose gel electrophoresis. The results indicated that the ASOs were completely encapsulated by all DPPs except DPP10 and DPP12, when the N/P molar ratio was higher than 4 (Fig. 1b and Additional file 1: Figure S4). As the electrostatic interaction is the main force between DPPs and ASOs, the fewer positive charges in DPP would lead to the weaker interactions, and ultimately the lower encapsulation efficacy. The N/P molar ratio $=8$ was chosen for the preparation of $A D$ and DP-AD in the following study to avoid high cytotoxicity and high clearance rate of NPs caused by high N/P molar ratio as reported previously $[19,30]$. The encapsulation rates of ASOs were above $85 \%$ when the N/P molar ratio was 8 (Additional file 1: Fig. S5a, b). Then, we optimized the molar ratio of DSPE-mPEG2000. We had previously confirmed that AD7 could effectively deliver ASOs into bacteria when incubated in dd $\mathrm{H}_{2} \mathrm{O}$ (data not shown), while the delivery efficiency decreased significantly when treated with $\mathrm{M}-\mathrm{H}$ broth 
(Additional file 1: Fig. S6a), which was caused by the aggregation of AD7 in the complicated medium (Fig. 1d). The flow cytometry results indicated that DP-AD7 got the highest delivery efficiency when the molar ratio of DSPE-mPEG2000 to ASO was 0.5: 1 (Additional file 1: Fig. S6a). Furthermore, the growth curve results showed that DP-AD7 with the same DSPE-mPEG2000 ratio (0.5: 1) had the highest inhibitory efficacy compared to the counterpart mismatched group (Additional file 1: Fig. S6b-e). DSPEmPEG2000 was a widely used phospholipids-polymer conjugate in drug delivery applications. It was a biocompatible, biodegradable and amphiphilic material which could be functionalized with various biomolecules for specific functions [31, 32]. In our DP-AD delivery system, lower ratio of DSPE-mPEG2000 would impair the stabilized efficacy of DSPE-mPEG2000, while higher ration would impair the cell membrane penetration efficacy of DP-AD. Then, we measured the binding efficiency of DSPE-mPEG2000 in DP-AD2, DP-AD3, DP-AD7 and DP-AD8, which were about 50\% (Additional file 1: Fig. S5c, d).

Then, we examined the formation of the intermediate product $A D$ by transmission electron microscopy (TEM) and dynamic light scattering (DLS). The results demonstrated that DPPs, except for DPP4, DPP5, DPP10 and DPP12, could form spherical AD, the diameters were ranging from $50 \mathrm{~nm}$ to $80 \mathrm{~nm}$ examined by TEM, or about $120 \mathrm{~nm}$ examined by DLS (Fig. 1c, d, Additional file 1: Figure S6). AD4 and AD5 were undetectable by neither DLS (data unshown) nor TEM, indicating the unsuccessful formation of NPs by these two DPPs. The excessive hydroxyl groups in DPP4 and DPP5 made them have stronger hydrophilic interactions with the solvent than with the ASOs during the preparation of AD. By contrast, the DLS results of $A D 10$ and AD12 showed notably larger sizes (>200 nm) compared with the other ADs, probably because there were only 6 positive charges in DPP10 or DPP12, leading to the looser interaction between these two DPPs and ASOs than those of other DPPs and evident aggregation between NPs (Additional file 1: Figure S6). Notably, the size of successfully prepared ADs increased sharply after being diluted with $\mathrm{M}-\mathrm{H}$ broth (Fig. 1d), suggesting that these intermediate products were aggregated in complicated solutions. After being decorated by DSPE-mPEG2000 (the molar ratio of DSPE-mPEG2000 to ASOs was 0.5), the DP-ADs products were virtually spherical (Fig. 1e, Additional file 1: Figure S7) and exhibited high stability, because their size did not change greatly after dilution in $50 \% \mathrm{M}-\mathrm{H}$ broth (Fig. 1f). The zeta potential of DP-ADs was about $+33 \mathrm{mV}$ (Fig. 1f), which is desirable for nano-delivery systems [33]. DLS results showed that the size of DP-ADs were 130-150 nm, showing a narrow distribution, which were larger than the values measured by TEM $(60-80 \mathrm{~nm})$ (Fig. 1e and Additional file 1: Table S4), consistent with the previous evidences attesting that the hydrodynamic diameters measured by DLS were larger than the solid diameters measured by TEM [34, 35]. Notably, DLS and TEM results of the linear DP-AD (LDP-AD) were consistent with those of DPP7 (Fig. 1d, f, Additional file 1: Figure S7), indicating the successful preparation of L-DP-AD. Given that DPP4, DPP5, DPP10 and DPP12 could not form stable nanoparticles with ASOs, they were excluded in the following experiments.

\section{Screening of DP-AD}

To explore the critical factors that determine the penetration efficacy of DPP and screen the DP-AD with the highest delivery efficacy in bacteria, the Gram-negative $E$. coli and ESBLs-E. coli and Gram-positive $S$. aureus and MRSA were incubated with FAM-labeled DP-ADs at $37^{\circ} \mathrm{C}$ for $1 \mathrm{~h}$ away from light. Then, the 
FAM-positive bacterial ratio was measured by flow cytometry. The results showed that free ASOs without any carrier could hardly be internalized by all the tested strains, while the amphipathic DP-AD2, DP-AD3, DP-AD 7 and DP-AD8 showed an uptake efficiency of about $90 \%$ by the tested strains, significantly higher than that of commercially available transfection reagent LF2000-NPs which showed positive ratios about $50 \%-75 \%$. On the other hand, the bacteria treated by hydrophilic DP-AD1 or DP-AD6 and amphipathic DPAD9 or DP-AD 11 with four His residues exhibited the lowest uptake efficiency of $10 \%$ to $45 \%$ (Fig. 2a, b, Additional file 1 Figure S8 and Table S5), suggesting that the hydrophilicity of DPP and excessive His residues in DPP may hamper the uptake process of NPs. Both His and Arg residue contained a positive charge, but the mechanism for the impeding effect of excessive amount of His residues to the delivery efficiency of DP-AD needed further study. The failure of DPP10, DPP12 and L-DPP to deliver ASOs into $E$. coli and ESBLs-E. coli (Additional file 1: Figure S9) further confirmed that, the amphipathic and dendritic structure of DPP and the positive charge numbers played key roles in the delivery process. Consistent with the above results, DPP4 and DPP5 lacked the capacity of ASOs delivery in the tested bacterial strains (Additional file 1: Figure S9). Through this screening experiment, the amphipathic DP-AD2, DP$A D 3, D P-A D 7$ and DP-AD8 with positive charges $\geq 8$ possessed a high capability to deliver ASOs into bacterial strains and were selected for further experiment.

Although DP-AD2, DP-AD3, DP-AD7 and DP-AD8 had similar delivery capacity in the tested strains, whether these DP-ADs could release the cargos and exert antisense inhibitory effects in bacteria remains unclear. Thus, we prepared DP-ADs targeting egfp or $\operatorname{acp} P\left(\mathrm{DP}-\mathrm{AD} \mathrm{D}_{\text {anti-egfp }}\right.$ or DP-AD $\left.\mathrm{D}_{\text {anti-acpP }}\right)$ and tested their antisense inhibitory efficacy on $E$. coli expressing enhanced green fluorescent protein (EGFP) or ESBLs-E. coli, respectively. Flow cytometry showed that $1 \mu \mathrm{M}$ DP-AD7 ${ }_{\text {anti-egfp }}$ and DP-AD8 anti-egfp significantly reduced the GFP fluorescent intensity of bacteria compared with the control and mismatched groups. However, DP-AD2 $2_{\text {anti-egfp }}$ and DP-AD3 ${ }_{\text {anti-egfp }}$ with the same concentration showed no effects on the GFP fluorescent intensity (Fig. 2b). Consistently, the growth curve results showed that $1 \mu \mathrm{M}$

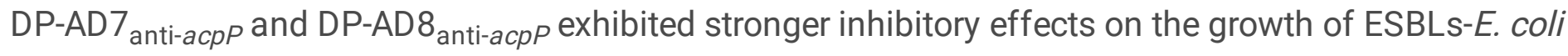
than DP-AD2 anti-acpP, $_{\text {DP-AD3 }}$ anti-acpP, or the mismatched group (DP-AD7 mismatch) (Fig. 2c). These data furtherly confirmed that the presence of two His residues in DPP was beneficial to the transfection efficiency of ASOs in bacteria by DP-ADs. As DP-AD2, DP-AD3 had the similar delivery efficiency with DP$A D 7$ and DP-AD8, it is reasonable to infer that His residues may promote the release of ASOs from DPAD7 and DP-AD8 after entering bacterial cells. These results were in accordance with a previous study demonstrating that the "proton-sponge effect" of His residues in CPPs promotes the escape of NPs from endosomes, thus enhancing the transfection efficiency in host cells $[24,36]$. However, as far as we knew, it was unclear that whether bacteria had endosomes or the similar structures like in mammalian cells, which is an open question for further research. We also observed evident antibacterial effects of $1 \mu \mathrm{M}$

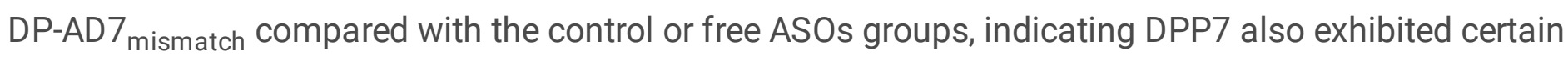
antibacterial activity. To further validate the antibacterial activity of DPPs, minimum inhibitory concentration (MIC) assays revealed that all the amphipathic DPPs (DPP2, DPP3, DPP7 and DPP8) showed antibacterial activity against E. coli, ESBLs-E. coli, S. aureus and MRSA. And the MICs of DPP7 and DPP8 for the tested bacteria were $16-32 \mu \mathrm{g} \mathrm{mL}^{-1}$ (Additional file 1: Table S6). The antibacterial 
activity of these DPPs would be caused by the positive charge of DPPs, which can be further modified to enhance their antibacterial activity and develop bifunctional antibacterial agents in the future. We also measured the cytotoxicity of DP-AD2, DP-AD3 and DP-AD7, the results showed that free DPPs and DPADs showed no observable cytotoxicity in normal human small intestine epithelial cells (HIEC) (Additional file 1: Figure S10).

\section{The delivery efficacy of DP-AD and its bacteria spectrum for delivery}

Given the results that DP-AD7 and DP-AD8 had similar delivery profiles and antisense efficacy, DP-AD7 was selected as the representation to study their antibacterial efficacy in vitro and in vivo.

Firstly, we explored the delivery potential of DP-AD to carry ASOs into different bacterial strains, FAMlabeled DP-AD7 was incubated with Gram-negative ESBLs-E. coli (ATCC35218), K. pneumonia (ATCC75293), MDR-A. baumannii (XJ17014279) and MDR-P. aeruginosa and Gram-positive MRSA, $B$. subtilis (ATCC23857), MRSE and E. faecalis (ATCC29212), respectively. Then the fluorescent positive ratios were measured by flow cytometry. The results showed that all the tested strains had a positive ratio up to $90 \%$ with different fluorescent intensities, except for MDR-P. aeruginosa, which had a positive ratio about $85 \%$ with the fluorescent intensity significantly lower than other tested strains (Fig. 3a). It is well known that $P$. aeruginosa had the intrinsic resistance to many kinds of small molecular antibiotics because of the poor permeability of the outer membrane [37], which also hindered the delivery efficiency of DP-AD7.

Then we further explored the dynamic features of the uptake process of DP-AD7 in different bacterial strains. FAM-labeled DP-AD7 were incubated with ESBLs-E. coli, E. coli, S. aureus and MRSA for 5, 10, 30 and 60 min, respectively. Then FAM-positive bacterial ratio was measured. The results showed that the FAM-positive bacterial ratio reached the peak value at $10 \mathrm{~min}$ in E. coli and ESBLs-E. coli, while at $30 \mathrm{~min}$ in S. aureus and MRSA (Fig. 3b). These results indicated that DP-AD7 could be internalized rapidly in both Gram-negative and Gram-positive bacteria. As the Gram-positive bacteria had thicker cell wall than Gramnegative bacteria, we hypothesized that the cell wall had a higher blocking influence on the delivery efficiency than the cellular membrane. To further ensure the delivery efficiency, bacteria and NPs were incubated for $1 \mathrm{~h}$ in different temperatures. As a result, no significant difference was observed between the uptake efficiency of DP-AD7 when incubated at $37^{\circ} \mathrm{C}$ or $4^{\circ} \mathrm{C}$ by all the four tested strains (Additional file 1: Figure S11), implying that the uptake process by bacteria is not dependent on temperature related processes, such as energy state $[38,39]$. However, the concrete uptake mechanism of DP-AD7 and the influence of the cell wall on the delivery process required further study.

To further confirm the potential of DP-AD7 to carry ASOs into bacteria, confocal laser scanning microscopy (CLSM) was adopted to observe the internalization of DP-AD7 by ESBLs- $E$. coli and $B$. subtilis. After incubation with FAM-labeled DP-AD7 in dark for $1 \mathrm{~h}$, strong green fluorescence was observed in the cytoplasm of both ESBLs-E. coli and B. subtilis (Fig. 3c), in contrast to the red fluorescence staining in the bacterial cell membrane labeled with FM4-64, indicating that DP-AD7 could be successfully internalized by the tested strains. From these data, DP-AD7 could efficiently deliver ASOs 
into a broad spectrum of bacteria, including the well-known MDR-A. baumannii and MDR-P. aeruginosa, which are intrinsic resistant to most antibiotics because of their low penetration of the outer membrane.

\section{Antisense antibacterial activity of DP-AD7 in vitro and in vivo}

Then, we studied the antibacterial activity of DP-AD7 in vitro and in vivo. We first studied the antisense inhibitory effect of DP-AD7 anti-acpP and DP-AD7 ${ }_{\text {anti-rpoD }}$ on E. coli and ESBLs-E. coli, S. aureus and MRSA, respectively. The results showed that DP-AD7 anti-acpP and DP-AD7 $7_{\text {anti-rpoD }}$ significantly inhibited the growth of the tested bacterial strains in a concentration dependent manner, showing a higher inhibition

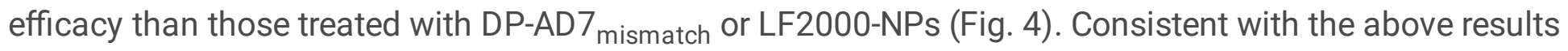
that DPP7 had intrinsic antibacterial effect, the 1 or $0.5 \mu \mathrm{M}$ DP-AD7 mismatch $_{\text {also showed a significant }}$ inhibitory effect compared with the control group (Additional file 1: Figure S12). When treated with 0.5 or $1 \mu \mathrm{M}$ DP-AD7, the knockdown efficiency of acpP in E. coli and ESBLs-E. coli and rpoD in S. aureus and MRSA were much higher than that of the mismatched counterpart groups as revealed by RT-PCR assay (Additional file 1: Figure S13). Importantly, DP-AD7 showed a stronger inhibition effect of gene expression compared with commercial LF2000-NPs. The linear counterpart, L-DP-AD anti-acpP $_{\text {or L-DP-AD }}$ anti-rpoD, showed neither growth inhibition nor gene suppression effect on the tested bacterial strains. These results demonstrated that DP-AD7 could significantly inhibit the bacterial growth and expression of target gene in vitro.

To explore the in vivo effect of DP-AD7, we firstly determined the distribution of DP-AD7 in mice by an in vivo imaging system. As a result, DP-AD7 was mainly distributed in the liver and kidney of mice 2 hours after intraperitoneal injection of cy5-labeled DP-AD7 (1.5 $\mathrm{mg} \mathrm{kg}^{-1}$, amounting to $225 \mathrm{nmol} \mathrm{kg}{ }^{-1}$ ASOs) (Fig. $5 a, b)$. Then, we studied the antibacterial efficacy of DP-AD7 anti-acpp in vivo. The mouse sepsis model was established by intraperitoneal administration of ESBLs-E. coli ( $4 \times 10^{5} \mathrm{CFU}$ in $0.4 \mathrm{~mL} \mathrm{M-H}$ broth) into each mouse (Male BALB/c, 8-10 weeks of age and weighing 18-22 g). These infected mice received different treatments (Fig. 5c), including control agents, different doses of DP-AD7 anti-acpP, DP-AD7 $_{\text {mismatch, L-DP- }}$

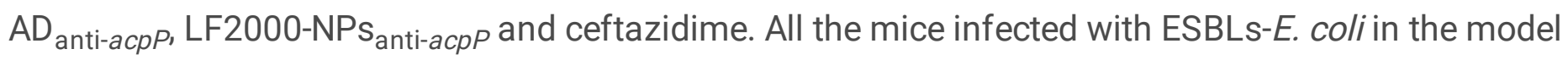
group died within $24 \mathrm{~h}$. The intraperitoneal administration of DP-AD7 $7_{\text {anti-acpP }}$ with doses ranging from 0.5 to $1.5 \mathrm{mg} \mathrm{kg}^{-1}$ (amounting to 75 to $225 \mathrm{nmol} \mathrm{kg}^{-1}$ ASOs, respectively) significantly improved the mice survival rate in a dose-dependent manner. The survival rates of mice treated with 1 or $1.5 \mathrm{mg} \mathrm{kg}^{-1} \mathrm{DP}$ $A D 7_{\text {anti-acp } P}$ were improved to $50 \%$ and $90 \%$, respectively. These values were significantly higher compared with that of DP-AD7 mismatch treated groups, which had $30 \%$ and $20 \%$ survival rates in 1 or 1.5 $\mathrm{mg} \mathrm{kg}^{-1}$ groups, respectively. Notably, the mice treated with $1.5 \mathrm{mg} \mathrm{kg}^{-1} \mathrm{LF}^{2000-N P s_{\text {anti-acp }} \text { or }}$ ceftazidime had a survival rate of $50 \%$ or $30 \%$, respectively, significantly lower than that of the DP-AD7 anti${ }_{a c p}$ treated group. Consistent with the results in vitro, DP-AD7 mismatch also showed protective effects on infected mice. The survival rate of the mice treated with L-DP-AD7 $7_{\text {anti-acp } P}$ was only about $20 \%$ (Fig. 5 d). The increased survival rate was associated with a reduction of the bacterial load in the liver and kidney, where the NPs mainly distributed (Fig. 5a, b), of mice inoculated with ESBLs-E. coli. Ten hours after 
infection, the average bacterial load in the kidney was $3.77 \pm 1.07 \times 10^{8} \mathrm{CFU} \mathrm{g}^{-1}$ in the model group, which was reduced to $1.24 \pm 1.80 \times 10^{5}$ or $1.80 \pm 2.28 \times 10^{3} \mathrm{CFU} \mathrm{g}^{-1}$ in the group treated with 1 or $1.5 \mathrm{mg} \mathrm{kg}^{-1} \mathrm{DP}$ $A D 7_{\text {anti-acp }}$, respectively. The bacterial load values in the DP-AD $7_{\text {anti-acp } P}$ treated groups were significantly lower than that of DP-AD $7_{\text {mismatch }}$ treated groups, which showed $7.39 \pm 1.51 \times 10^{7}$ and $3.40 \pm 1.77 \times 10^{9} \mathrm{CFU} \mathrm{g}^{-1}$, in mice groups treated with 0.5 and $1.5 \mathrm{mg} \mathrm{kg}^{-1} \mathrm{DP}-\mathrm{AD} 7_{\text {mismatch }}$, respectively. Meanwhile, the CFU number in the groups treated with $1.5 \mathrm{mg} \mathrm{kg}^{-1} \mathrm{LF}^{-2000-N P s_{\text {anti-acpP, }} \text { L-DP-AD }}$ anti-acpP $_{\text {. }}$ or ceftazidime were $1.58 \pm 1.49 \times 10^{8}, 3.85 \pm 4.80 \times 10^{8}$ or $8.41 \pm 1.60 \times 10^{7} \mathrm{CFU} \mathrm{g}^{-1}$, which were significantly

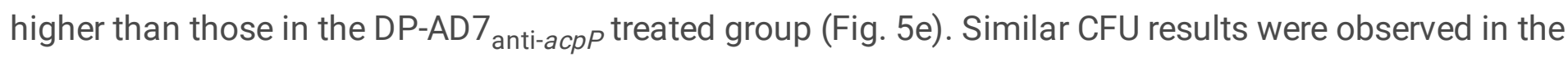
liver of the infected mice (Fig. 5f). Pathological analysis of the animal tissues indicated that, DP-AD7 anti${ }_{a c p}$ treatment significantly attenuated the lesion and congestion of the liver and kidney compared with those treated with DP-AD7 mismatch or ceftazidime (Additional file 1: Figure S14). Collectively, these results confirmed the strong antibacterial activity of DP-AD7 anti-acpP $_{\text {in mice infection model. }}$

\section{Conclusions}

We designed a series of DPPs with different hydrophobicity, positive charge distribution pattern and amino acid types, and prepared a novel type of DP-ADs non-covalently. We found that hydroxyl groups in DPPs and a positive charge number less than 8 would interfere the formation of NPs. The centralized distribution of positive charges could faciliate the delivery of DP-ADs, but an averaged distribution of positive charge would hamper this process. The amphipathic DPP2, DPP3, DPP7 and DPP8 showed a notably higher efficiency to deliver ASOs into Gram-negative and Gram-positive bacteria, whereas only amphipathic DPP7 and DPP8 with two His residues in sequence exhibited the best antisense inhibitory

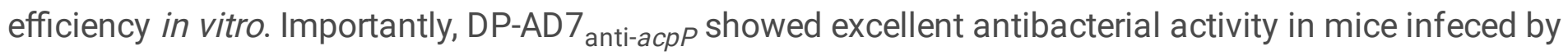
ESBLs-E.coli. Based on these results, the hydrophilic terminals in the DPPs with 8-12 positive charges are beneficial for complexion with ASOs. The hydrophobic terminals facilitate DPPs entering bacteria by strengthening their interactions with lipid-rich plasma membrane; whereas two His residues in DPPs promote the release of the loaded drug in the intracytoplasm of bacteria. In conclusion, we determined for the first time the key factors influencing the formation of DP-AD and the transfection efficiency in bacteria, and provide a novel approach for further research and application of antisense antibacterial stretagy.

\section{Methods}

\section{Materials}

DPPs (Scheme 1, Additional file 1: Table S1-S2 and Figure S1-S3) were synthesized by ChinaPeptides Co., Ltd. (Suzhou, China). 2'-0-methyl (2'-OMe) modified antisense oligonucleotides (ASOs), 5'-fluorescein amidites (FAM)-labeled ASOs and primers were synthesized by Sangon Biotech (Shanghai, China) (Additional file 1: Figure S3). 5'-Cyanine 5 (Cy5)-labeled ASOs were synthesized by Tsingke Biological 
Technology Co., Ltd (Xi'an, China). 1,2-distearoyl-sn-glycero-3-phosphoethanolamine-Nmethoxy(polyethylene glycol)-2000 (DSPE-mPEG2000) was purchased from Xi'an ruixi Biological Technology Co., Ltd. Trizol (Additional file 1: Figure S3), FM4-64 dye, Lipofectamine $2000^{\mathrm{TM}}$ and OptiMEM medium were purchased from Life Technologies (Invitrogen, CA, USA). Lysogeny broth and MuellerHinton (M-H) broth were purchased from Beijing Land Bridge Technology Co., Ltd (Beijing, China). Reversed enzyme and SYBER Green enzyme were purchased from Takara Bio Inc. (Kyoto, Japan).

\section{Bacterial strains and cell line}

Escherichia coli (E. coli, ATCC25922), extended spectrum ß-lactamase-producing Escherichia coli (ESBLsE. coli, ATCC35218), Klebsiella pneumonia (K. pneumonia, ATCC75293), multidrug resistant Pseudomonas aeruginosa (MDR-P. aeruginosa), Staphylococcus aureus (S. aureus, ATCC29213), Escherichia faecalis (E. faecalis, ATCC29212) and Bacillus subtilis (B. subtilis, ATCC23857) were stored in our laboratory, methicillin-resistant Staphylococcus epidermidis (MRSE), methicillin-resistant Staphylococcus aureus (MRSA), Multidrug-resistant Acinetobacter baumannii (MDR-A. baumannii XJ17014279) was isolated from Xijing Hospital, Fourth Military Medical University. E. coli (DH5a) were obtained from Beijing Beina Chuanglian Biotechnology Institute.

\section{Nanoparticles (NPs) preparation}

LF2000-NPs were prepared in strict accordance with the protocol described in our previous study [40]. DPP storing solutions (Additional file 1: Table S3) were diluted 50 times to obtain the working solutions. DSPE-mPEG2000 decorated DPP/ASOs nanoparticles (DP-ADs) were prepared in two steps. Firstly, the DPP working solution $(3 \mu \mathrm{l})$ and ASOs $(15 \mu \mathrm{l}, 20 \mu \mathrm{M})$ dissolved in RNAse/DNAse free sterile water (0.02 $\mathrm{mM}$ ) were diluted to $275 \mu \mathrm{l}$ by RNAse/DNAse free sterile water and mixed at $2600 \mathrm{rpm}$ for $1 \mathrm{~min}$, followed by incubation at $37^{\circ} \mathrm{C}$ for $30 \mathrm{~min}$ to form DPP/ASOs nanoparticles (ADs). Secondly, $7.5 \mu \mathrm{LSPE}-$ mPEG2000 solution ( $20 \mu \mathrm{M}, 0.5$-fold of ASOs) was added into the ADs solutions, and the mixture was mixed at $2600 \mathrm{rpm}$ for $1 \mathrm{~min}$ and incubated at $37^{\circ} \mathrm{C}$ for another $30 \mathrm{~min}$ to obtain the DP-AD solution (1 $\mu \mathrm{M})$, whose concentration was calculated based on the concentration of ASOs. DP-ADs with different DSPE-mPEG2000 ratios were prepared with the same preduure with different DSPE-mPEG2000 volumes. The linear DP-AD (L-DP-AD) were prepared with the same procedure used for DP-ADs.

\section{Agarose gel electrophoresis}

The ASOs solution was incubated with DPPs at $37^{\circ} \mathrm{C}$ for 30 min at geometric N/P molar ratios ranging from 0 to 16 to form ADs. The prepared ADs $(10 \mu \mathrm{l}, 40 \mu \mathrm{M})$ were analyzed by electrophoresis on agarose gel ( $1 \% \mathrm{wt} / \mathrm{vol})$ and stained with ethidium bromide to obtain the images.

\section{Transmission electrom microscope (TEM)}

TEM was adopted to observe the morphology of the NPs. Briefly, a drop of NPs solution ( $30 \mu \mathrm{M})$ was added to slide-grids, followed by natural settling for $5 \mathrm{~min}$ in ambient conditions before the liquid was 
sucked away quickly. Then, the grids were dried in ambient condtions. Images were captured using JEM1230 Electron Microscope (JEOL, Japan) at 80 kV.

\section{Size and zeta potential measurement}

DP-ADs size and zeta potential were measured by zeta sizer (Marlvern Panalytical, UK). The NPs solution $(1 \mathrm{ml})$ was added into a disposable cuvette with an optical path of $1 \mathrm{~cm}$. The measurement conditions for size were as following: the dispersant was water; Mark-Houwink parameters were 0.428 (A parameter) and $7.67 \times 10^{-5}$ (K parameter); measurement temperature was $25^{\circ} \mathrm{C}$; the measurement angle was $173^{\circ}$. The NPs solution (approximately $1 \mathrm{ml}$ ) was added into a disposable folded capillary cell, followed by the measurement of the zeta potential at $25^{\circ} \mathrm{C}$. The sizes of DP-AD in M-H broth were measured after $500 \mu \mathrm{l}$ NPs solution were diluted with an equal volume of $\mathrm{M}-\mathrm{H}$ broth. The analysis was performed in triplicate by Zetasizer software (version 7.13, Malvern).

\section{Bacterial culture}

Bacteria stored in $15 \%$ glycerine were streaked onto $\mathrm{M}-\mathrm{H}$ agarose plate and cultured at $37^{\circ} \mathrm{C}$ for $18 \mathrm{~h}$. Next, a bacterial colony was transferred from the M-H agarose plate into Lysogeny broth (LB, $3 \mathrm{ml}$ ) in quartz tubes and cultured at $37^{\circ} \mathrm{C}$ until reaching the logarithmic growth stage.

\section{Flow cytometry analysis}

To measure the delivery efficiency, FAM-labeled DP-ADs were added to bacterial cultures (approximately $5 \times 10^{6} \mathrm{CFU}$ in $300 \mu \mathrm{l}$ - $\mathrm{H}$ broth) and incubated at $37^{\circ} \mathrm{C}$ for $1 \mathrm{~h}$ away from light. The bacterial solutions were centrifuged at $2500 \mathrm{~g}$ at $4{ }^{\circ} \mathrm{C}$ for $5 \mathrm{~min}$ and washed twice with phosphate buffered saline (PBS) before analyzing them using the BL1 (green) channel in flow cytometry (Novocyte, Acer, USA). Data were analyzed using Flowjo software (version 10.0.7, Tree Star, Ashland, OR, USA). Free FAM-labeled ASOs and LF2000-NPs were used as the negative and positive control, respectively.

To measure the delivery rate of DP-AD7 in different types of bacteria, the bacteria (approximately $5 \times 10^{6}$ CFU in $300 \mu \mathrm{l} \mathrm{M-H} \mathrm{broth)} \mathrm{were} \mathrm{incubated} \mathrm{with} \mathrm{FAM-labeled} \mathrm{DP-AD7} \mathrm{for} 5,10,30$ or 60 min at $37^{\circ} \mathrm{C}$ or at 4 ${ }^{\circ} \mathrm{C}$ for $60 \mathrm{~min}$ in dark, then the bacterial solutions were processed, measured and analyzed as described above.

E. coli (DH5a), an engineering bacterial strain expressing EGFP, was adopted to measure the antisense efficacy of DP-AD in vitro. $3 \times 10^{6} \mathrm{CFU}$ bacteria in $300 \mu \mathrm{l}$-H broth were treated with $300 \mu \mathrm{l}$ amphipathic DP-AD2, 3, 7 or 8 solutions $(1 \mu \mathrm{M})$ at $37^{\circ} \mathrm{C}$ for $1 \mathrm{~h}$. Then, fluorescence intensity was measured by flow cytometry and analyzed as described above.

The FAM positive rates of ESBLs-E. coli (ATCC35218), K. pneumoniae (ATCC75293), MDR-P. aeruginosa, E. faecalis (ATCC29212), B. subtilis (ATCC23857), MRSE, MRSA and MDR-A. baumannii (XJ17014279) were measured as following: $3 \times 10^{6} \mathrm{CFU}$ bacteria in $300 \mu \mathrm{L} \mathrm{M-H}$ broth were incubated with $300 \mu \mathrm{L} \mathrm{DP}$ - 
AD7 at $37^{\circ} \mathrm{C}$ for $1 \mathrm{~h}$. Then, fluorescence intensity was measured by flow cytometry and analyzed as described above.

\section{Confocal laser scanning microscope (CLSM)}

Firstly, cy5-labeled DP-AD7 solution $(300 \mu \mathrm{l}, 2 \mu \mathrm{M})$ was incubated with ESBLs-E. coli or B. subtilis $\left(10^{7}\right.$ $\mathrm{CFU}$ in $300 \mu \mathrm{l} \mathrm{M-H}$ broth) for $1 \mathrm{~h}$ at $37^{\circ} \mathrm{C}$ away from light. Secondly, the bacterial solution were centrifuged at $2500 \mathrm{~g}$ for $5 \mathrm{~min}$ to discard the supernatant, and washed twice with $500 \mu \mathrm{l}$ PBS, followed by resuspension of the bacteria with $20 \mu$ PBS. Then, $1 \mu$ FM4-64 dye was added into the bacterial solutions to stain the plasma membrane at ice for $1 \mathrm{~min}$, then, the solutions were centrifuged at $2500 \mathrm{~g}$ for $5 \mathrm{~min}$, discarded the supernatant, and resuspended the bacteria with $20 \mu \mathrm{lPBS}$. Then, several drops of these solutions were added onto a 0.5 -cm cover glass and dried at $37^{\circ} \mathrm{C}$, followed by the addition of a drop of glycerin $50 \%$ to fix the bacteria. Lastly, CLSM was adopted to measure bacterial fluorescence. Images were captured and analyzed by Olympus Fluoview Viewer (version 3.0, Olympus Corp., Japan).

\section{Minimum inhibitory concentration (MIC)}

DPP bacterial toxicity was evaluated by MIC assay of DPPs in E. coli, ESBLs-E. coli, S. aureus and MRSA. Briefly, DPP (50 $\mu \mathrm{l}$, with a geometric concentrations ranging from $64 \mu \mathrm{g} \mathrm{ml}^{-1}$ to $0.5 \mu \mathrm{g} \mathrm{ml}^{-1}$ dissolved in M$\mathrm{H}$ broth) was added into 96 -well plates, followed by the addition of an equal volume of the tested bacterial solutions (approximately $10^{6} \mathrm{CFU}$ ). Then, the mixture was incubated at $37^{\circ} \mathrm{C}$ for $24 \mathrm{~h}$ and the optical density was measured using Bio-Rad 680 microplate reader (BioRad Corporate, Hercules, California, USA).

\section{mRNA quantification}

Bacterial solutions (approximately $3 \times 10^{7} \mathrm{CFU}$ in $300 \mu \mathrm{l}$-H broth) were incubated with DP-AD (300 $\mu \mathrm{l}, 3$ $\mu \mathrm{M}$ ) at $37^{\circ} \mathrm{C}$ for $3 \mathrm{~h}$. Bacterial total RNA was extracted using Trizol (Invitrogen, CA, USA). RNA was reversely transcribed to cDNA using HiScript ${ }^{\mathrm{TM}}$ Reverse Transcriptase (Vazyme Biotech co., Ltd) and mRNA was quantified using SYBR green detection kit following the manufacturer's instructions with a Real-Time Q-PCR System (Mx3005p, Agilent Technologies StrataGene, La Jolla, CA, USA). The antisense sequences were 5'-cttcgatagtg-3' for $\operatorname{acp} P[37,41], 5^{\prime}$-acagctcctcgcccttcg-3' for egfp in E. coli and ESBLsE. coli, while 5'-tttctcgtca-3' for rpoD in $S$. aureus and MRSA. The primers used were the following: $E$. coli 16 s ribosomal RNA (rRNA) forward 5'-cggacgggtgagtaatgt-3' and reverse 5'-gtgcttcttctgcgggta-3'; acpP forward 5'-gagaattcatgagcactatcgaagaac-3' and reverse 5'-agttaagcttgaccgcctggagatgttc-3'. S. aurues 16s rRNA forward 5'-cgtggataacctacctataagact-3' and reverse 5'-gattccctactgctgcctc-3', rpoD forward 5'cagatactgacgagaaa-3' and 5'- gaataacataccacgac-3'. The PCR results in the tested strains were normalized using $16 s$ rRNA as the housekeeping gene. Results were presented as the average fold change relative to the untreated control group by $2^{-\Delta \Delta C t}$ method.

\section{Bacterial growth curve}


E. coli solution in LB was centrifuged at $2500 \mathrm{~g}$ for $5 \mathrm{~min}$ at $4{ }^{\circ} \mathrm{C}$ and resuspended in $\mathrm{M}-\mathrm{H}$ broth. Bacterial solutions $\left(10^{6} \mathrm{CFU}\right.$ in $300 \mu \mathrm{M}$-H broth) were mixed with $300 \mu \mathrm{LP}-\mathrm{AD}_{\text {anti-acpP }}$ (E. coli and ESBLs-E. coli) or DP-AD ${ }_{\text {anti-rpoD }}(S$. aureus or MRSA) solutions. The mixtures were divided into three wells on a culture plate and incubated into BioScreen $\mathrm{C}$ analyser at $37^{\circ} \mathrm{C}$ for $18 \mathrm{~h}$ to measure the optical density per hour. Data were plotted and analyzed by Graphpad Prism (version 5.00, GraphPad Software, Inc., La Jolla, CA, USA).

\section{In vivo fluorescent image acquisition}

$400 \mu \mathrm{l}$ DP-AD7 was adminstered into male Balb/c mice intraperitoneally, and the fluorescent images of the mice were acquired after $2 \mathrm{~h}$. Then, the mice were sacrificed and the fluorescent images of the organs (heart, liver, spleen, lung and kidney) were acquired by an in vivo imaging system.

\section{Survival assay of DP-AD7 on infected animals}

Male Balb/c mice (6-8 weeks old and weighing 18-22 g) were used in this experiment. The experimental and animal care procedures were approved by the Animal Care and Use Committee of Fourth Military Medical University. All methods were carried out strictly in accordance with the approved guidelines. $4 \times 10^{5}$ CFU ESBLs-E. coli in $400 \mu \mathrm{M}-\mathrm{H}$ broth were adminstrated intraperitoneally into the mice to construct a sepsis model. Then, the mice were randomly divided to ten groups, which were administered intraperitoneally with $400 \mu \mathrm{L}$ solutions containing 0.5 (based on ASOs), 1 or $1.5 \mathrm{mg} \mathrm{kg}^{-1}$ DP-AD7 anti-acpP and the counterpart DP-AD7 mismatch $_{1.5 \mathrm{mg} \mathrm{kg}^{-1} \text { L-DP-AD7 }}$ anti-acpP, $1.5 \mathrm{mg} \mathrm{kg}^{-1}$ LF2000-NPS $_{\text {anti-acpP, }} 4 \mathrm{mg}$ $\mathrm{kg}^{-1}$ ceftazidime or PBS at 0.5 and $6 \mathrm{~h}$ after infection. The surviving mice in each group were monitored every six hour for the first day, afterwards, monitored every $12 \mathrm{~h}$ for 7 days day after infection, and the survival ratio was analyzed by Kaplan-Meier estimator.

Two mice in each group were sacrificed $10 \mathrm{~h}$ after infection to study the bacterial clearance. The liver and kidney were harvested aseptically, one kidney and one lobe of liver of each mice were weighed, and homogenized in $500 \mu \mathrm{l}$ sterile saline solution, then $50 \mu \mathrm{l}$ homogenate sample of each mice was performed serial 10 -fold dilutions to a $10^{-5}$ dilution. Carefully spread $100 \mu \mathrm{L}$ of each dilution onto a $\mathrm{M}-\mathrm{H}$ agarose plate using a glass spreader. Incubate plates at $37^{\circ} \mathrm{C}$ overnight and calculate the bacterial load. Colony counts were expressed as $\mathrm{CFU} \mathrm{g}^{-1}$ of tissue.

The other kidney and liver lobe of each mice were stored in $4 \%$ paraformaldehyde, paraffin embedding and hematoxylin and eosin staining were performed to observe the tissue lesions. The staining processes of tissues were carried out by the technicians in Department of Pathology, Fourth Military Medical University. The images were capture on Olympus BX15 with DP controller (version 3.1.1.267, Olympus Corp., Japan).

\section{Statistical Analysis}


Results are expressed as mean values ( \pm SE). Statistical analyses were performed with SPSS (version 20.0.0, IBM Corp., Armonk, NY, USA). Differences between two groups were compared using $t$ tests, and groups of two or more were compared to the control group using Dunnett $t$ tests.

\section{Declarations}

\section{Acknowledgments}

We acknowledge Dr. Deqin Kong (Department of Toxicology, The Fourth Military Medical University, Xi'an, China) and Haifeng Zhang (Department of Neurobiology, The Fourth Military Medical University, Xi'an, China) for the help for the CLSM experiment.

\section{Author contribution}

$\mathrm{ZC}$ and $\mathrm{XXue}$ developed the original ideas of the study. $\mathrm{ZC}$ and $\mathrm{YH}$ conducted most of the experiments. $Z C, X M a o$ and $X X$ wrote the manuscript, DN, HZ, ZH, ML, JM helped to edit and revise the manuscript, XX and $\mathrm{XL}$ were the corresponding author. All authors read and approved the final manuscript.

\section{Funding}

This study were supported by the National Natural Science Foundation of China (No. 82002187 and No. 81972359, China) and Fourth Military Medical University JSTS201805.

\section{Availability of data and materials}

All data generated or analysed during this study are included in this published article.

\section{Ethics approval and consent to participate}

All of the cell and animal studies were approved by the Animal Care and Use Committee of Fourth Military Medical University.

\section{Consent for publication}

All authors agree to be published.

\section{Competing interest}

All authors declare that they have no competing interests.

\section{Authors' information}

${ }^{1}$ Department of Pharmacology, School of Pharmacy, Fourth Military Medical University, Xi'an, Shaanxi, 710032, China. ${ }^{2}$ Department of Neurosurgery of Xijing Hospital, Fourth Military Medical University, Xi'an, Shaanxi, 710032, China. 


\section{References}

1. R. Sharma, C. L. Sharma, B. Kapoor. Antibacterial resistance: Current problems and possible solutions. Indian J Med Sci. 2005, 59, 120-9.

2. H. Pirvanescu, M. Balasoiu, M. E. Ciurea, A. T. Balasoiu, R. Manescu. Wound infections with multidrug resistant bacteria. Chirurgia (Bucur). 2014, 109, 73-9.

3. A. P. Wilson, D. M. Livermore, J. A. Otter, R. E. Warren, P. Jenks, D. A. Enoch, et al. Prevention and control of multi-drug-resistant gram-negative bacteria: Recommendations from a joint working party. J Hosp Infect. 2016, 92 Suppl 1, S1-44.

4. R. Penchovsky, M. Traykovska. Designing drugs that overcome antibacterial resistance: Where do we stand and what should we do? Expert Opin Drug Discov. 2015, 10, 631-50.

5. R. Pifer, D. E. Greenberg. Antisense antibacterial compounds. Transl Res. 2020, 223, 89-106.

6. L. Good, S. K. Awasthi, R. Dryselius, O. Larsson, P. E. Nielsen. Bactericidal antisense effects of peptide-pna conjugates. Nat Biotechnol. 2001, 19, 360-4.

7. C. Torres Viera, S. Tsiodras, H. S. Gold, E. P. Coakley, C. Wennersten, G. M. Eliopoulos, et al. Restoration of vancomycin susceptibility in enterococcus faecalis by antiresistance determinant gene transfer. Antimicrob Agents Chemother. 2001, 45, 973-5.

8. S. Liang, Y. He, Y. Xia, H. Wang, L. Wang, R. Gao, et al. Inhibiting the growth of methicillin-resistant staphylococcus aureus in vitro with antisense peptide nucleic acid conjugates targeting the ftsz gene. Int J Infect Dis. 2015, 30, 1-6.

9. H. Bai, G. Sang, Y. You, X. Xue, Y. Zhou, Z. Hou, et al. Targeting rna polymerase primary sigma70 as a therapeutic strategy against methicillin-resistant staphylococcus aureus by antisense peptide nucleic acid. Plos One. 2012, 7, e29886.

10. H. Bai, Y. You, H. Yan, J. Meng, X. Xue, Z. Hou, et al. Antisense inhibition of gene expression and growth in gram-negative bacteria by cell-penetrating peptide conjugates of peptide nucleic acids targeted to rpod gene. Biomaterials. 2012, 33, 659-67.

11. J. Meng, H. Wang, Z. Hou, T. Chen, J. Fu, X. Ma, et al. Novel anion liposome-encapsulated antisense oligonucleotide restores susceptibility of methicillin-resistant staphylococcus aureus and rescues mice from lethal sepsis by targeting meca. Antimicrob Agents Chemother. 2009, 53, 2871-8.

12. H. Wang, J. Meng, M. Jia, X. Ma, G. He, J. Yu, et al. Oprm as a new target for reversion of multidrug resistance in pseudomonas aeruginosa by antisense phosphorothioate oligodeoxynucleotides. FEMS Immunol Med Microbiol. 2010, 60, 275-82.

13. L. Good, R. Sandberg, O. Larsson, P. E. Nielsen, C. Wahlestedt. Antisense pna effects in escherichia coli are limited by the outer-membrane Ips layer. Microbiology (Reading). 2000, 146 (Pt 10), 266570 .

14. X. Y. Xue, X. G. Mao, Y. Zhou, Z. Chen, Y. Hu, Z. Hou, et al. Advances in the delivery of antisense oligonucleotides for combating bacterial infectious diseases. Nanomedicine-Uk. 2018, 14, 745-58. 
15. D. Lyrawati, A. Trounson, D. Cram. Expression of gfp in the mitochondrial compartment using dqasome-mediated delivery of an artificial mini-mitochondrial genome. Pharm Res. 2011, 28, 284862.

16. B. Du, L. Tian, X. Gu, D. Li, E. Wang, J. Wang. Anionic lipid, ph-sensitive liposome-gold nanoparticle hybrids for gene delivery - quantitative research of the mechanism. Small. 2015, 11, 2333-40.

17. W. Shen, Q. Wang, Y. Shen, X. Gao, L. Li, Y. Yan, et al. Green tea catechin dramatically promotes rnai mediated by low-molecular-weight polymers. ACS Cent Sci. 2018, 4, 1326-33.

18. J. Zhou, K. T. Shum, J. C. Burnett, J. J. Rossi. Nanoparticle-based delivery of rnai therapeutics: Progress and challenges. Pharmaceuticals (Basel). 2013, 6, 85-107.

19. E. Blanco, H. Shen, M. Ferrari. Principles of nanoparticle design for overcoming biological barriers to drug delivery. Nat Biotechnol. 2015, 33, 941-51.

20. J. B. Readman, G. Dickson, N. G. Coldham. Tetrahedral DNA nanoparticle vector for intracellular delivery of targeted peptide nucleic acid antisense agents to restore antibiotic sensitivity in cefotaxime-resistant escherichia coli. Nucleic Acid Ther. 2017, 27, 176-81.

21. F. Wang, Y. Wang, X. Zhang, W. Zhang, S. Guo, F. Jin. Recent progress of cell-penetrating peptides as new carriers for intracellular cargo delivery. J Control Release. 2014, 174, 126-36.

22. Z. Chen, D. Nie, Y. Hu, M. Li, Z. Hou, X. Mao, et al. Efficient delivery of antisense oligonucleotides by an amphipathic cell-penetrating peptide in acinetobacter baumannii. Curr Drug Deliv. 2019, 16, 72836.

23. A. Kwok, G. A. Eggimann, J. L. Reymond, T. Darbre, F. Hollfelder. Peptide dendrimer/lipid hybrid systems are efficient DNA transfection reagents: Structure-activity relationships highlight the role of charge distribution across dendrimer generations. Acs Nano. 2013, 7, 4668-82.

24. K. K. Hou, H. Pan, L. Ratner, P. H. Schlesinger, S. A. Wickline. Mechanisms of nanoparticle-mediated sirna transfection by melittin-derived peptides. Acs Nano. 2013, 7, 8605-15.

25. L. Crombez, G. Aldrian-Herrada, K. Konate, Q. N. Nguyen, G. K. McMaster, R. Brasseur, et al. A new potent secondary amphipathic cell-penetrating peptide for sirna delivery into mammalian cells. $\mathrm{Mol}$ Ther. 2009, 17, 95-103.

26. K. K. Hou, H. Pan, G. M. Lanza, S. A. Wickline. Melittin derived peptides for nanoparticle based sirna transfection. Biomaterials. 2013, 34, 3110-9.

27. G. Lattig-Tunnemann, M. Prinz, D. Hoffmann, J. Behlke, C. Palm-Apergi, I. Morano, et al. Backbone rigidity and static presentation of guanidinium groups increases cellular uptake of arginine-rich cellpenetrating peptides. Nat Commun. 2011, 2, 453.

28. K. Shinoda, A. Carlsson, B. Lindman. On the importance of hydroxyl groups in the polar head-group of nonionic surfactants and membrane lipids. Adv Colloid Interface Sci. 1996, 64, 253-71.

29. K. M. Wiencek, M. Fletcher. Bacterial adhesion to hydroxyl- and methyl-terminated alkanethiol selfassembled monolayers. J Bacteriol. 1995, 177, 1959-66. 
30. A. D. Miller. Delivery of rnai therapeutics: Work in progress. Expert Rev Med Devices. 2013, 10, 781811.

31. J. Che, C. I. Okeke, Z. B. Hu, J. Xu. Dspe-peg: A distinctive component in drug delivery system. Curr Pharm Des. 2015, 21, 1598-605.

32. M. Korani, S. Nikoofal-Sahlabadi, A. R. Nikpoor, S. Ghaffari, H. Attar, M. Mashreghi, et al. The effect of phase transition temperature on therapeutic efficacy of liposomal bortezomib. Anticancer Agents Med Chem. 2020, 20, 700-8.

33. S. Honary, F. Zahir. Effect of zeta potential on the properties of nano-drug delivery systems - a review (part 2). Trop J Pharm Res. 2013, 12, 265-73.

34. A. Monga, B. Pal. Enhanced stability, conductance, and catalytic activity of gold nanoparticles via oxidative dissolution by $\mathrm{kmno}_{4}$. Particul Sci Technol. 2015, 33, 159-65.

35. J. H. Jegal, G. H. Choi, H. J. Lee, K. D. Kim, S. C. Lee. Surface engineering of titanium with simvastatin-releasing polymer nanoparticles for enhanced osteogenic differentiation. Macromol Res. 2016, 24, 83-9.

36. M. Shi, J. Zhang, Z. Huang, Y. Chen, S. Pan, H. Hu, et al. Stimuli-responsive release and efficient sirna delivery in non-small cell lung cancer by a poly(l-histidine)-based multifunctional nanoplatform. $J$ Mater Chem B. 2020, 8, 1616-28.

37. A. Lupo, M. Haenni, J. Y. Madec. Antimicrobial resistance in acinetobacter spp. And pseudomonas spp. Microbiol Spectr. 2018, 6, ARBA-0007-2017.

38. M. L. Jobin, I. D. Alves. On the importance of electrostatic interactions between cell penetrating peptides and membranes: A pathway toward tumor cell selectivity? Biochimie. 2014, 107 Pt A, 1549.

39. A. Rydstrom, S. Deshayes, K. Konate, L. Crombez, K. Padari, H. Boukhaddaoui, et al. Direct translocation as major cellular uptake for cady self-assembling peptide-based nanoparticles. Plos One. 2011, 6, e25924.

40. Z. Chen, Y. Hu, J. Meng, M. Li, Z. Hou, Y. Zhou, et al. Efficient transfection of phosphorothioate oligodeoxyribonucleotides by lipofectamine2000 into different bacteria. Curr Drug Deliv. 2016, 13, 784-93.

41. S. M. Daly, C. R. Sturge, C. F. Felder-Scott, B. L. Geller, D. E. Greenberg. Mcr-1 inhibition with peptideconjugated phosphorodiamidate morpholino oligomers restores sensitivity to polymyxin in escherichia coli. Mbio. 2017, 8, e01315-17.

\section{Figures}


a

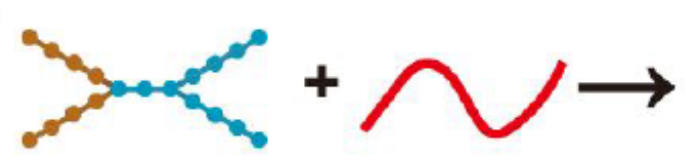

DPP

ASOs

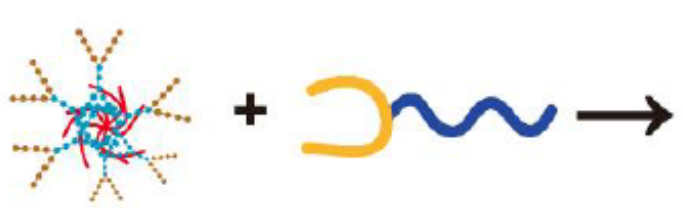

AD

DSPE-mPEG2000
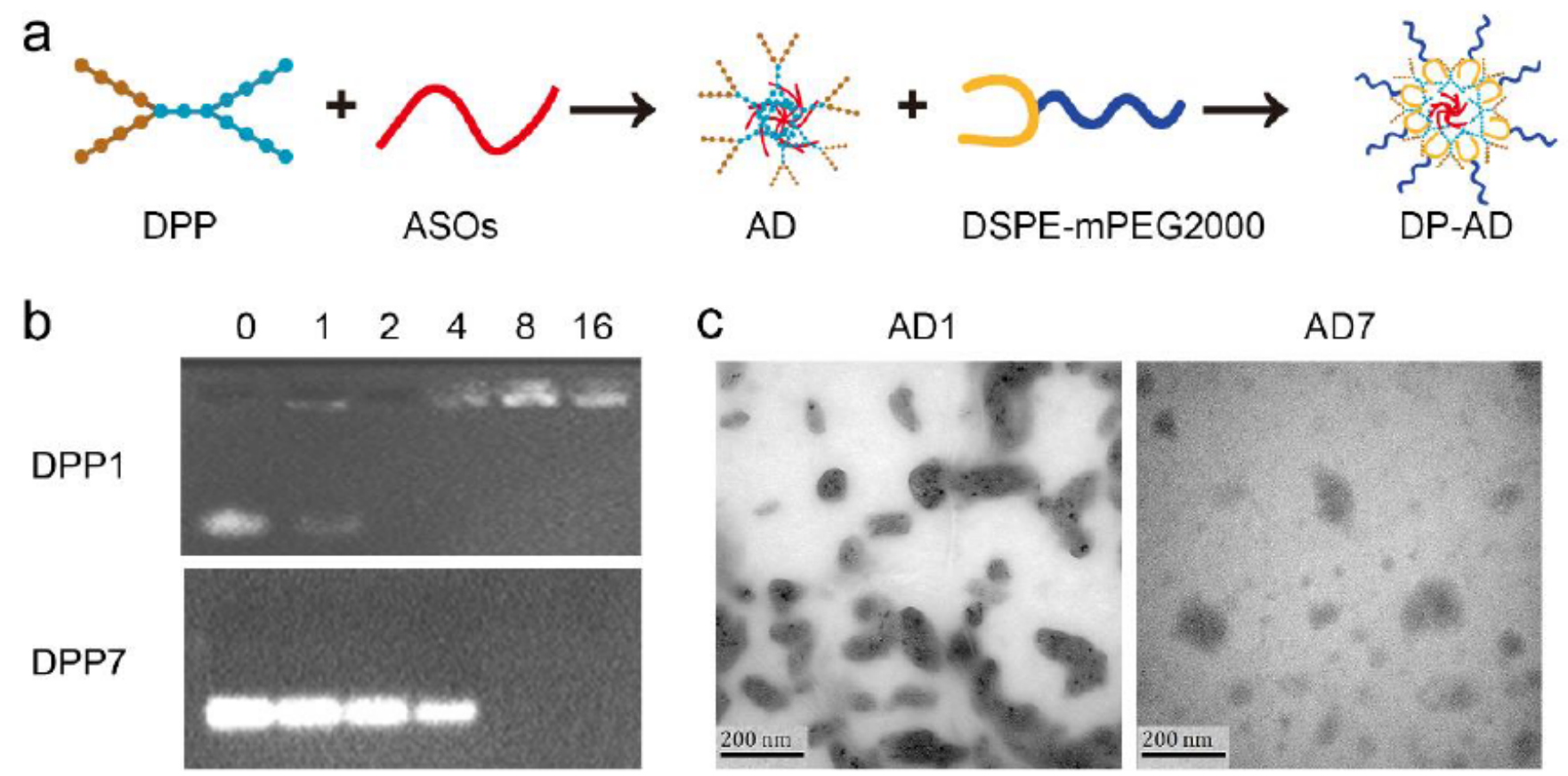

C

AD1

AD7

d

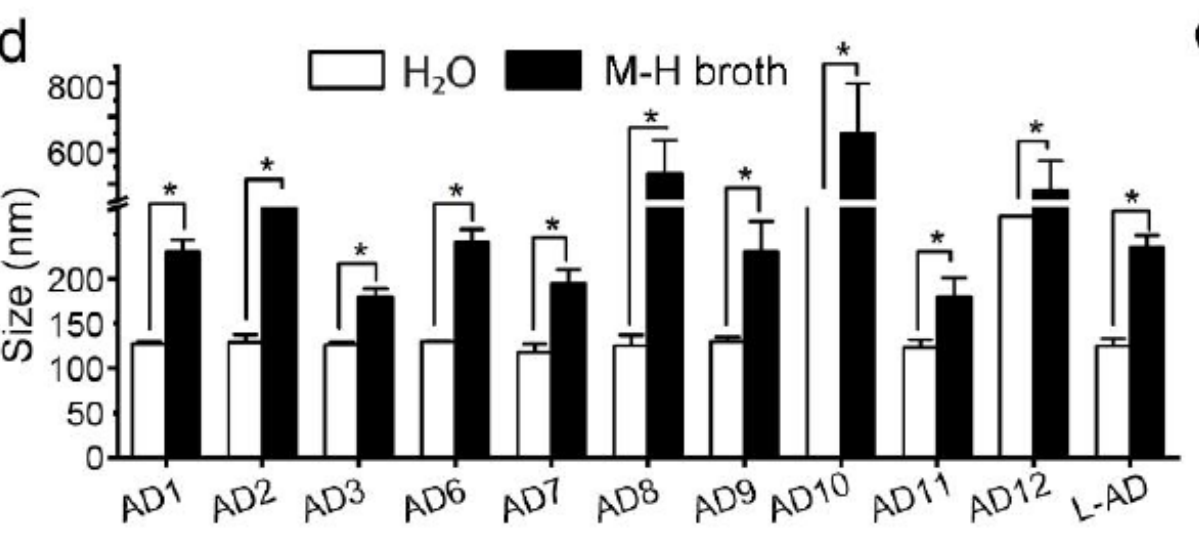

e
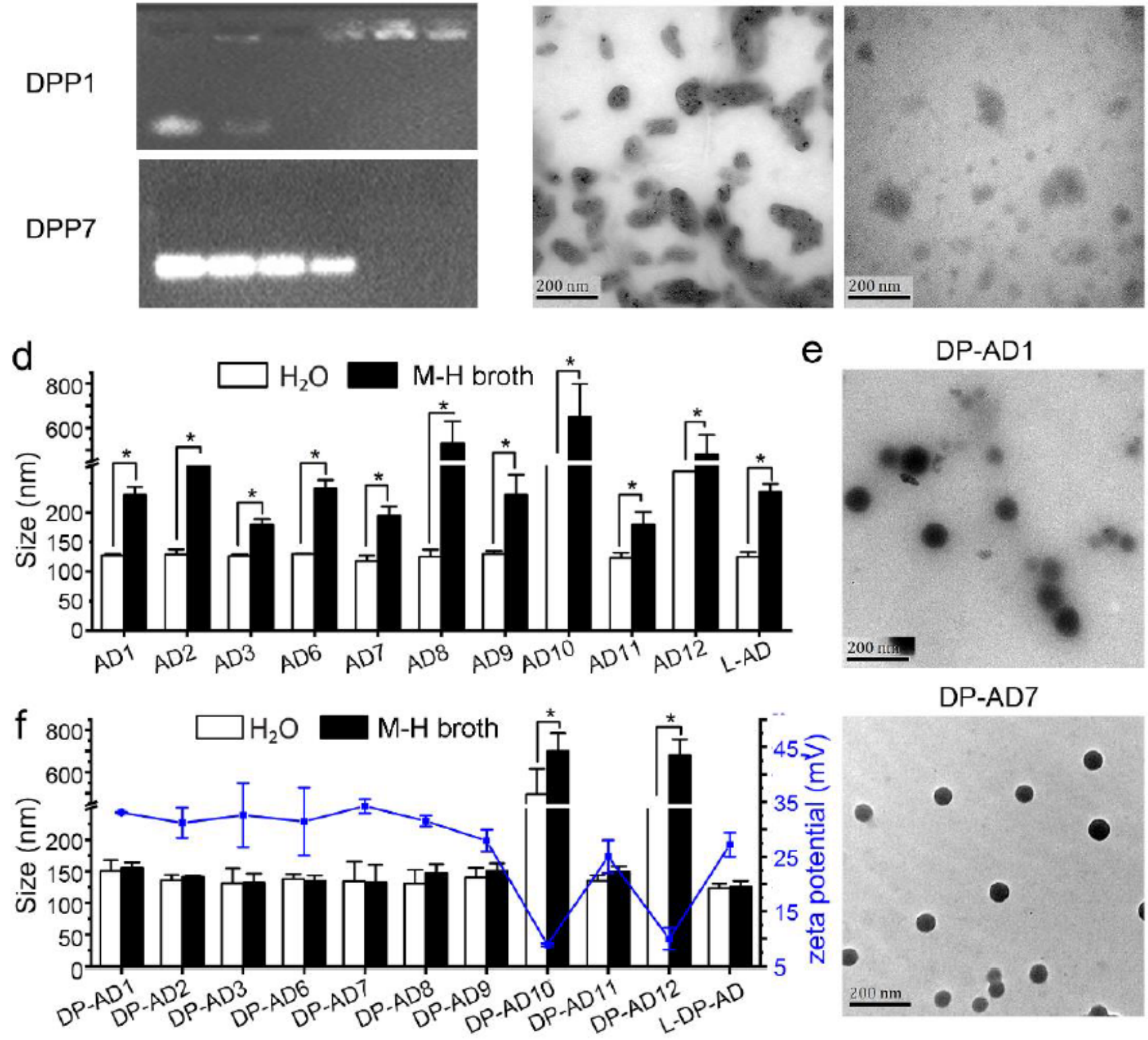

DP-AD7

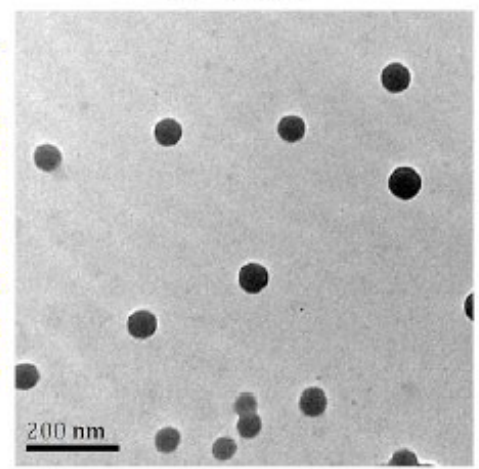

\section{Figure 1}

Preparation and characteristics of DP-ADs. a Schematic of the two-step preparation of DP-ADs. b Screening of the best N/P molar ratios ranging from 1 to 16 by $1 \%$ agarose gel electrophoresis. The upper and lower images indicated hydrophilic DP-AD1 and amphipathic DP-AD7, respectively. c TEM images of $A D 1$ and $A D 7$. $d$ The size of $A D s$ in dd $\mathrm{H} 20$ (white columns) and diluted with equal volume of $\mathrm{M}-\mathrm{H}$ broth (black columns). e TEM images of DP-AD1 and DP-AD7. $f$ The size of DP-ADs in dd H2O (white columns) 
and diluted with equal volume of M-H broth (black columns), and zeta potential (blue line) of DP-ADs in dd $\mathrm{H} 20$ determined by DLS. Bar $=200 \mathrm{~nm}$.

ESBLs-E. coli

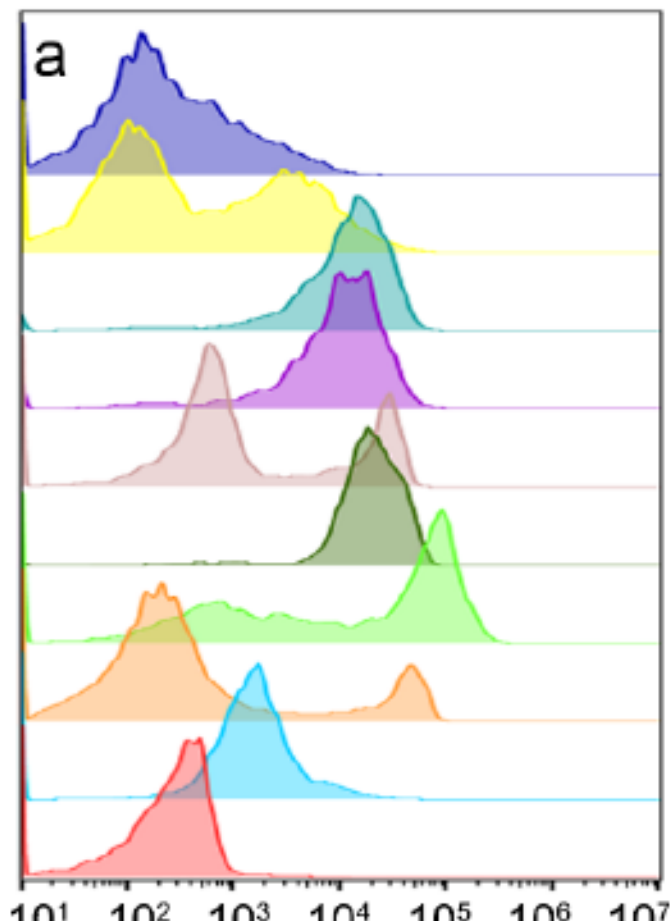

$\begin{array}{lllllll}10^{1} & 10^{2} & 10^{3} & 10^{4} & 10^{5} & 10^{6} & 10^{7}\end{array}$

Fluorescence Intensity

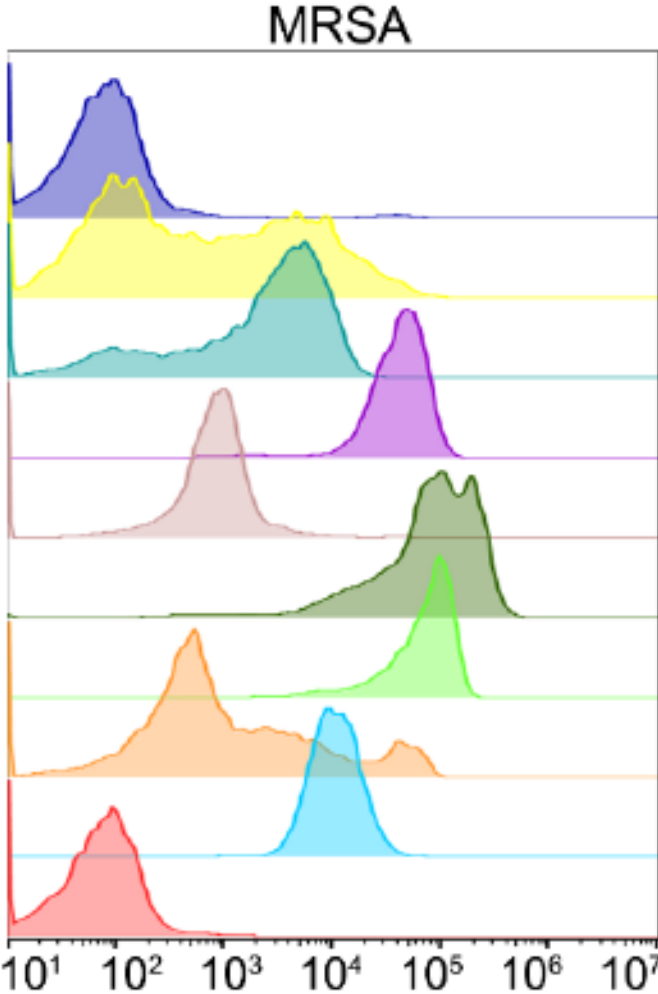

Fluorescence Intensity
- DP-AD11

DP-AD9

- DP-AD8

- DP-AD7

DP-AD6

- DP-AD3

DP-AD2

DP-AD1

- LF2000-NPs

Free ASOs

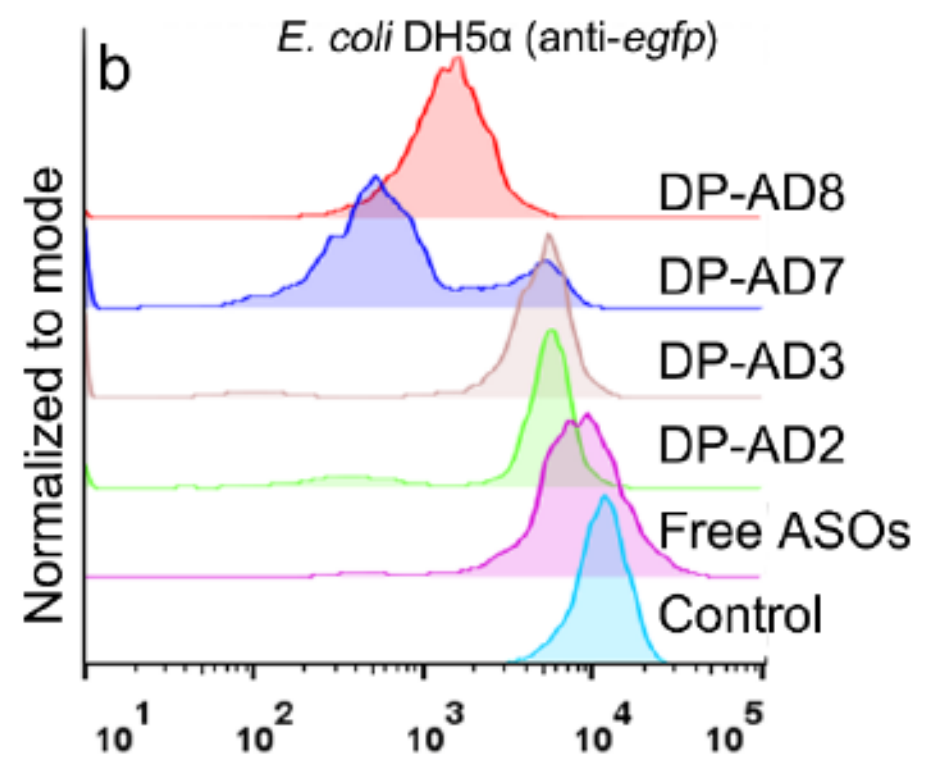

Fluorescence Intensity

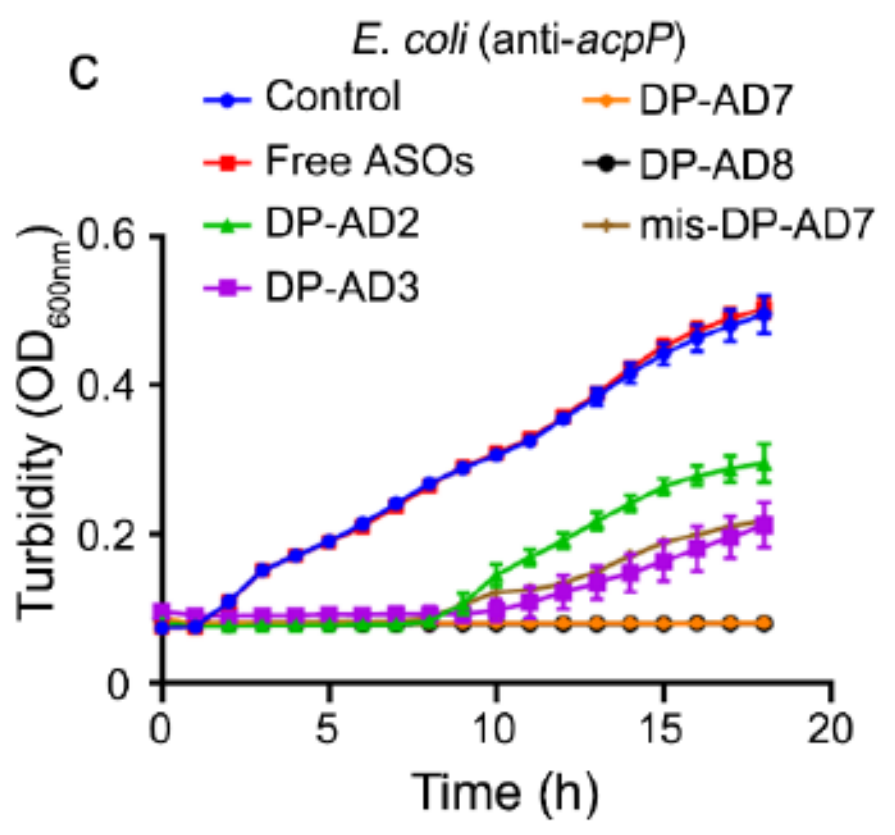

Figure 2

Screening the DP-ADs by delivery efficiency and antisense efficacy in vitro. a FAM-positive ratio of ESBLsE. coli (left) and MRSA (right) were tested by flow cytometry after incubation with FAM-labeled DP-ADs for $1 \mathrm{~h}$ in dark at $37^{\circ} \mathrm{C}$. Free FAM-labeled ASOs (red) and LF2000-NPs (light blue) were used as negative and 
positive controls, respectively. b GFP fluorescence intensity of E. coli (DH5a) expressing the GFP measured by flow-cytometry after incubation with $1 \mu \mathrm{M}$ DP-ADsanti-egfp for $3 \mathrm{~h}$. c Growth curves of ESBLs-E. coli treated with different amphipathic DP-ADsanti-acpP $(1 \mu \mathrm{M})$, OD600nm, the optical density at $600 \mathrm{~nm}$.
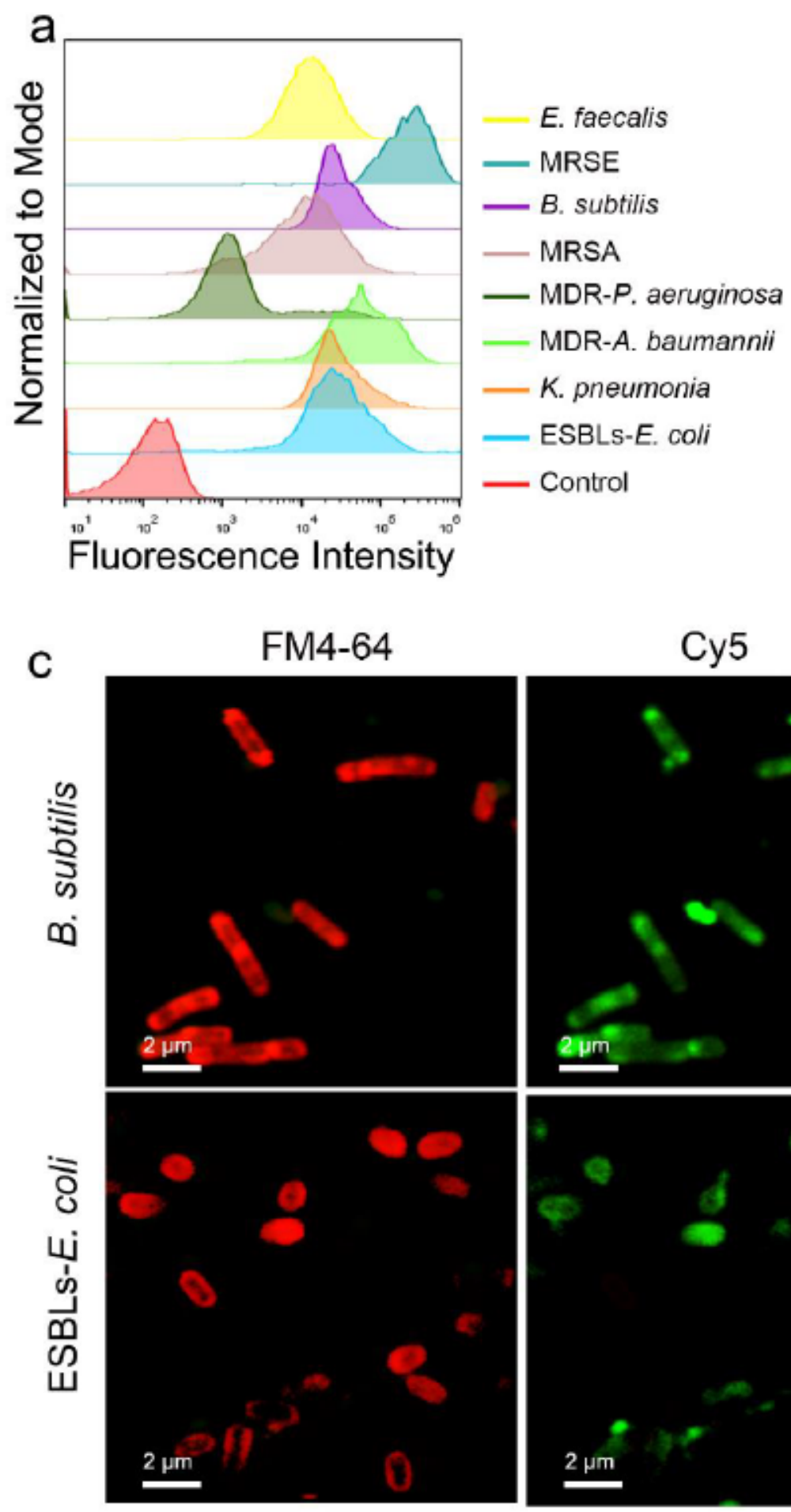

Cy5 b
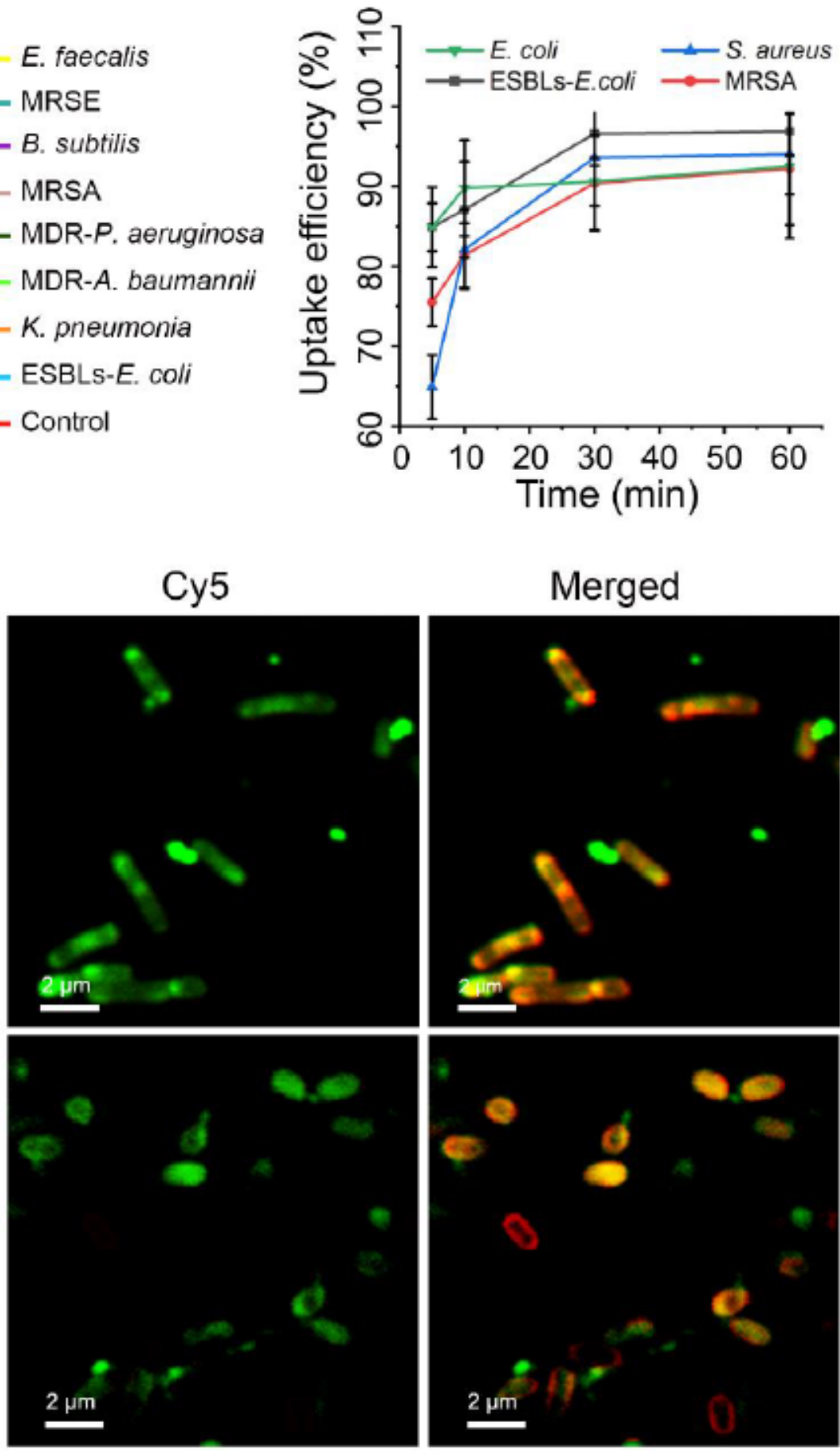

Merged
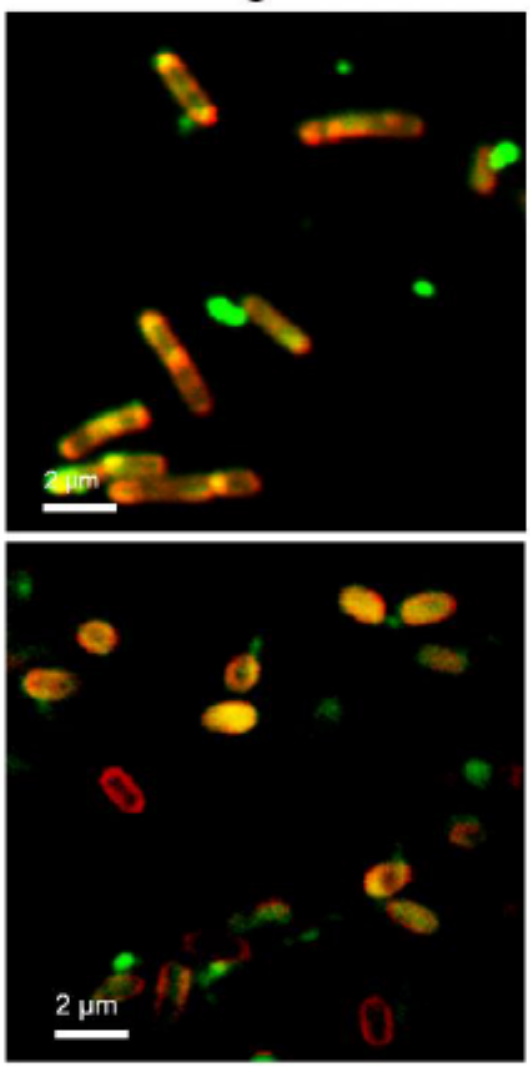

Figure 3 
Uptake profiles of DP-AD7. a Fluorescence positive ratios of ESBLs-E. coli, K. pneumoniae, MDR-A. baumannii, MDR-P. aeruginosa, MRSA, B. subtilis, MRSE and E. faecalis measured by flow-cytometry after incubation with $1 \mu \mathrm{M}$ FAM labeled DP-AD7 for $1 \mathrm{~h}$ in dark. $\mathrm{b}$ The FAM positive rate of the tested bacterial strains measured by flow cytometry after incubation with FAM-labeled DP-AD7 in the dark at $37^{\circ} \mathrm{C}$ for 5 , 10, 30 and 60 min. c CLSM images of ESBLs-E. coli (upper panel) and B. subtilis (lower panel) after incubation with cy5-labeled DP-AD7 for $1 \mathrm{~h}$ in dark at $37^{\circ} \mathrm{C}$. FM4-64 was used to stain the bacterial cell membrane. Bar $=2 \mu \mathrm{m}$.
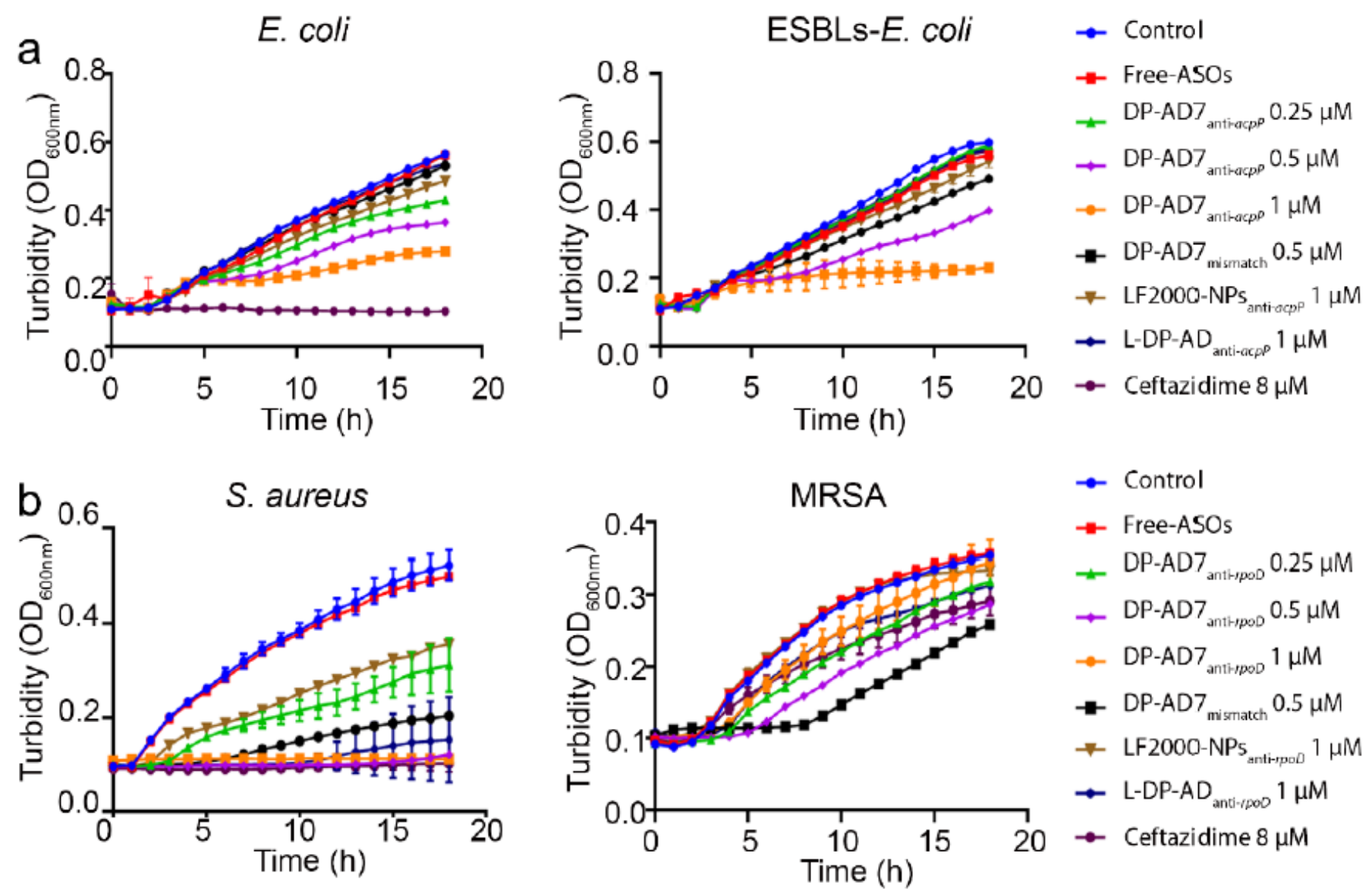

\section{Figure 4}

Antibacterial activity of DP-AD7 in vitro. (a) Growth inhibition of DP-AD7anti-acpP on E. coli (left) and ESBLs-E. coli (right) or (b) DP-AD7anti-rpoD on S. aureus (left) and MRSA (right) were measured. Ceftazidime and LF2000-NPsanti-acpP were used as positive control, and free ASOs and L-DP-AD were used as negative control. OD600nm, the optical density at $600 \mathrm{~nm}$. 

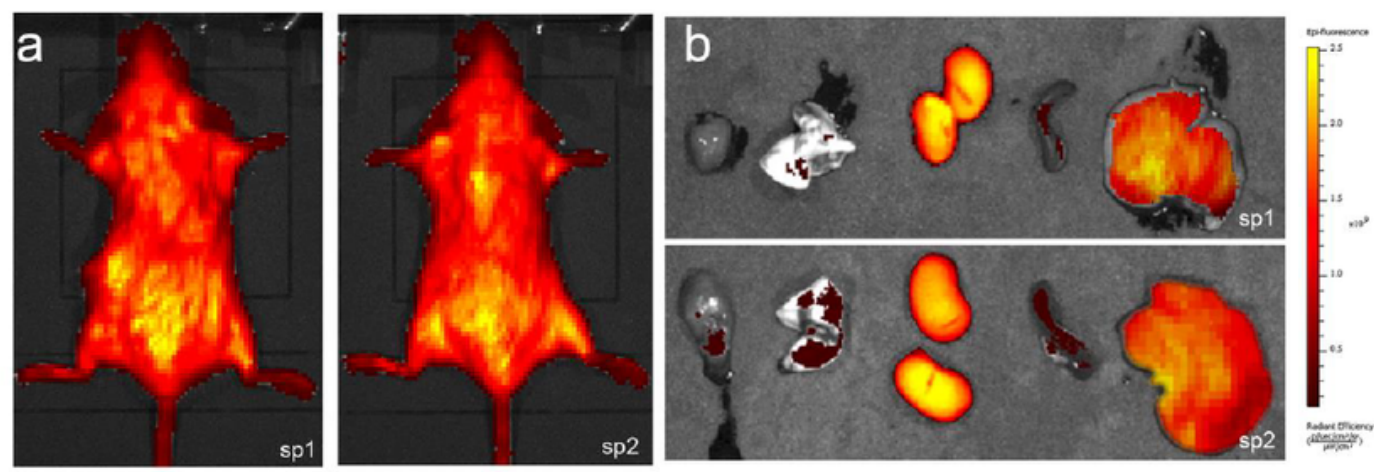

C

Second treatment
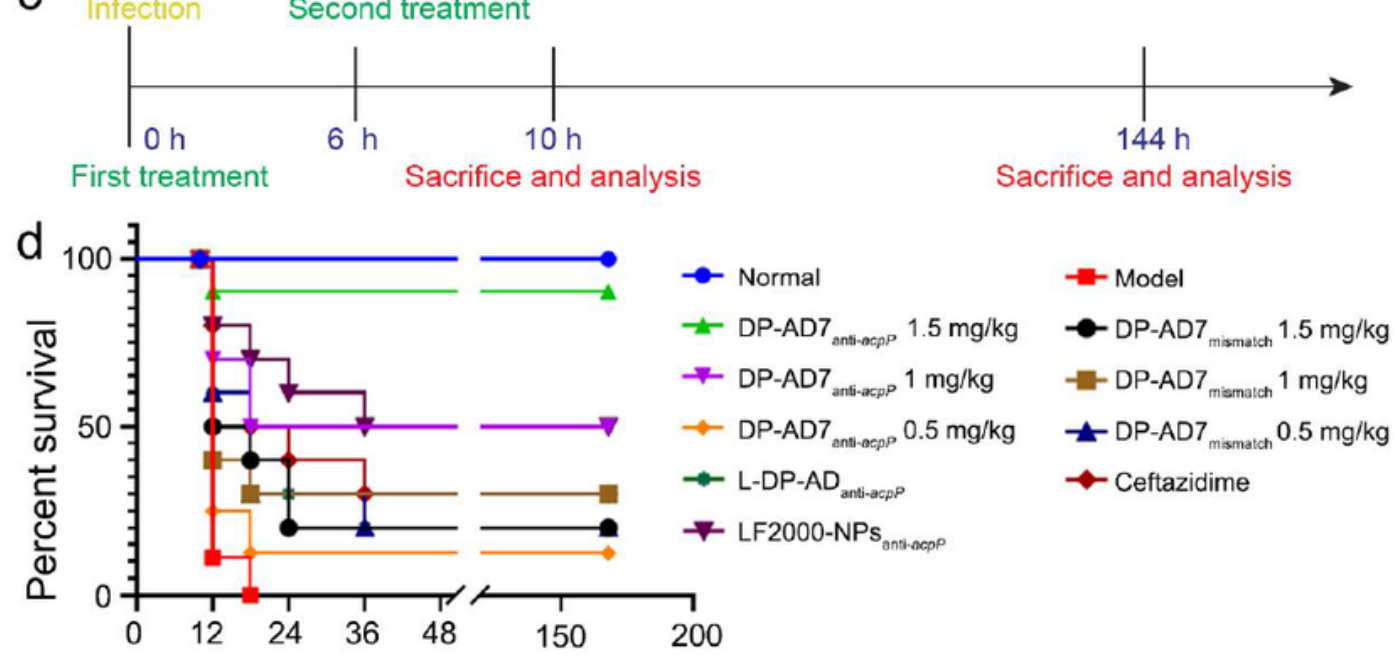

Time (h)
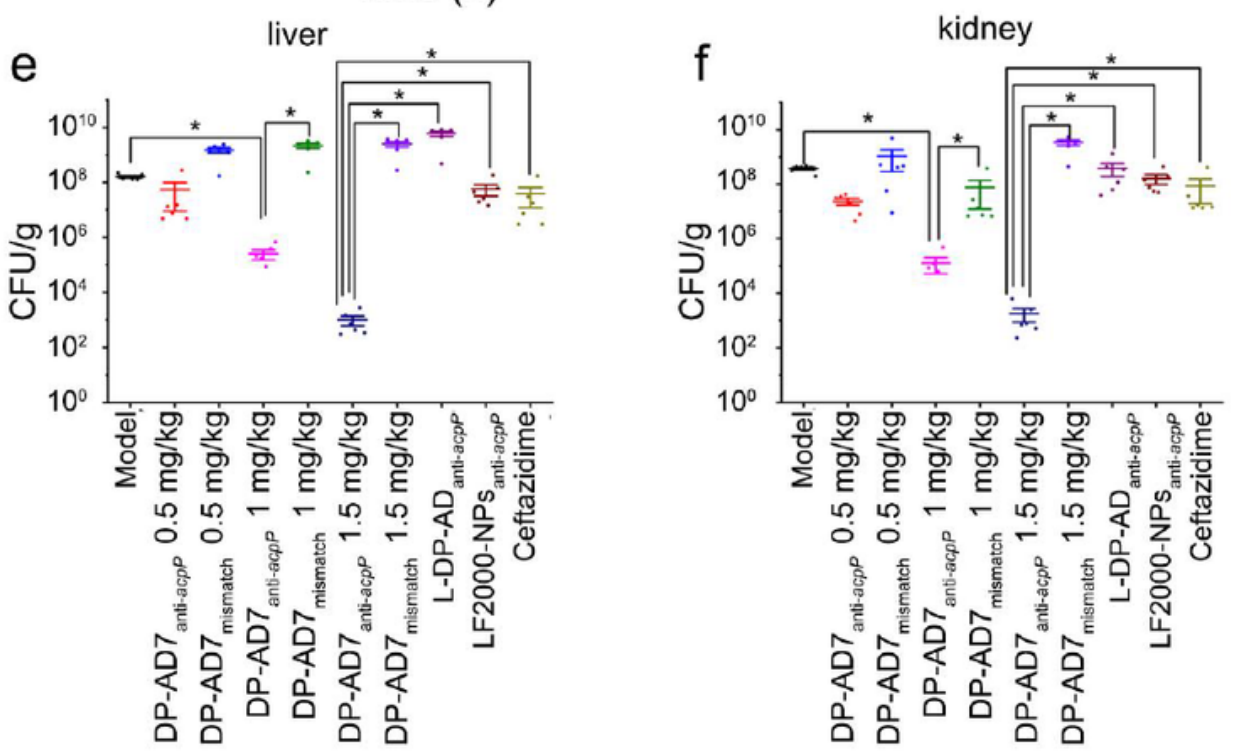

\section{Figure 5}

Antibacterial activity of DP-AD7anti-acpP against ESBLs-E. coli in the sepsis model. a, b Biodistribtution of DP-AD7anti-acpP in mice determined by in vivo imaging system. Mice were intraperitoneally administrated with $400 \mu \mathrm{l}$ cy5-labeled DP-AD7. Fluorescent signals were detected in the live mice (a) or the collected organs of the mice (b) 2 hours after injection. sp1 and sp2 were two independent samples. C The diagram of treatment and analysis procedure of the in vivo experiment. d Survival rate of BalB/c 
mice treated with DP-AD7anti-acpP (1.5, 1 and $0.5 \mathrm{mg} / \mathrm{kg})$, DP-AD7mismatch $(1.5,1$ or $0.5 \mathrm{mg} / \mathrm{kg})$, or LDP-ADanti-acpP $(1.5 \mathrm{mg} / \mathrm{kg})(\mathrm{n}=10)$. LF2000-NPsanti-acpP $(1.5 \mathrm{mg} / \mathrm{kg})$ and ceftazidime $(4 \mathrm{mg} / \mathrm{kg})$ were used as positive controls. e, $f$ Colonization of ESBLs-E.coli inocula in liver (e) and kidney ( $f$ ). Data represent the mean $\pm S E(n=6) .{ }^{\star} p<0.05$.

\section{Supplementary Files}

This is a list of supplementary files associated with this preprint. Click to download.

- Graphicalabstract.tif

- Scheme1.png

- Additionalfile1.docx 